\title{
A survey of modeling and control techniques for Micro- and Nano-electromechanical systems
}

\author{
Antoine Ferreira * $\quad$ Sumeet S. Aphale
}

\begin{abstract}
In the current times, MEMS and NEMS form a major inter-disciplinary area of research involving science, engineering and technology. A lot of work has been reported in the area of modeling and control of these devices, with the aim of better understanding their behavior and improving their performance. This work presents a review of the emerging advances in the modeling and control of these micro- and nanoscale devices and converges on the exciting research in onchip control, with a mechatronics and controls perspective and concludes by projecting future trends.
\end{abstract}

Index Terms-MEMS, NEMS, lab-on-a-chip, modeling, control

\section{INTRODUCTION}

Though micro-electromechanical systems (MEMS) and nano-electromechanical systems (NEMS) research has gained tremendous popularity and momentum in the past two decades, the potential of small micro-, nano- and even molecular machines was recognized by researchers, especially physicists and chemists almost half a century ago [1]. The race for miniaturizing had begun and finally in 1974, the term Nanotechnology was coined [2]. The development of 'cluster' science, [3], and the invention of the Scanning Tunneling Microscope, [4], in the early 1980s ushered the era of nanotechnology and the first book on this subject appeared in 1986, [5].

It is generally accepted that an electrostatically excited tuning fork employing field-effect transistor "readout" was the first operational MEMS device, [6]. Since then, the MEMS technology has progressed rapidly and in recent years specialized devices for applications such as blood cell separation and analysis are constantly expanding the boundaries of MEMS [7]. NEMS devices have also evolved since their first prototype was successfully demonstrated by researchers at IBM, [8]. Research aimed at developing specific sensor ([9], [10], [11]) and actuator ([12], [13], [14], [15], [16], [17], [18], [19]) technologies for improved MEMS and NEMS devices is ongoing. More details as to the current state-of-the-art for sensors and actuators can be found in [20].

Models that can capture the dynamic behavior of these devices can be of great help in understanding and improving their design and ultimately, their performance. Additionally, as with any dynamic system, a suitable control strategy could

Prof. Antoine Ferreira [Corresponding Author] is with the Institut PRISME, ENSI Bourges, 88 Boulevard Lahitolle, 18000 Bourges, France

Dr. Sumeet S. Aphale is a Research Fellow at the Center for Applied Dynamics Research (CADR), School of Engineering, Kings College, University of Aberdeen, UK

Copyright (c) 2008 IEEE. Personal use of this material is permitted. However, permission to use this material for any other other purposes must be obtained from the IEEE by sending a request to pubs-permissions@ieee.org align the actual performance of these MEMS/NEMS devices closer to the desired objectives. Therefore, the two key avenues of current engineering interest that have the potential to significantly enhance MEMS/NEMS devices are: (i) modeling and (ii) control. Modeling techniques that lead to a better understanding of these miniature device dynamics are currently being sought after. Accurate dynamic models could lead to specialized control strategies that will in turn lead to major improvements in device performances. In the recent years, a lot of research has been reported in the area of modeling and control of MEMS and NEMS. This paper presents an overview of the emerging innovative modeling techniques applicable to these miniature devices. Different models are presented for system design and control associated with physical mechanisms, geometry/scaling issues or computational aspect for real-time control of MEMS with challenging issues in NEMS. It also reviews the recent advances in the control of MEMS and NEMS devices that have been inspired by the recent innovations in sensors, actuators, modeling techniques and control theory.

\section{A. Organization}

The remainder of this review is organized as follows. Section II presents an overview of the various modeling innovations that describe the behavior of MEMS and NEMS devices. Complexity in modeling is reviewed with respect to associated physical mechanisms, geometry/scaling issues and computational aspect to minimize the real time control issues. This section is further divided into two parts viz: (i) Modeling for MEMS/NEMS design (subsection II-A), (ii) Modeling for MEMS/NEMS control (subsection II-B). Section III will review the various control technique implementations and is divided in to (i) Open-loop control (subsection III-A), (ii) Open-loop control with input pre-shaping (subsection III-B), (iii) Closed-loop control (subsection III-C) and (iv) On-chip control (subsection III-D). Section IV will present the possible future directions in modeling and control of MEMS and NEMS devices. Finally, section V will give the concluding remarks of this review.

\section{Models for System Design And Control}

Today, an abundance of commercial circuit and system simulation tools exist for electronic circuits and control system virtual prototyping. Microelectromechanical systems have been analyzed using the classical physical models or continuum theories for the mechanical (elastostatic or elastodynamic), the thermal (thermostatic), magnetic (magnetodynamics) and 


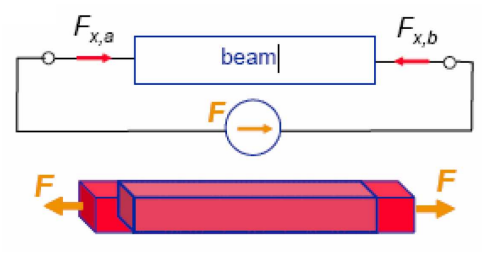

(a)

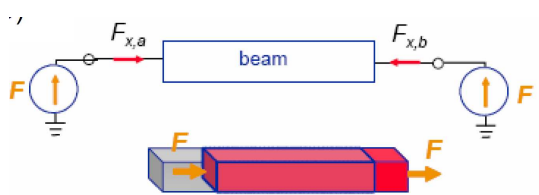

(b)

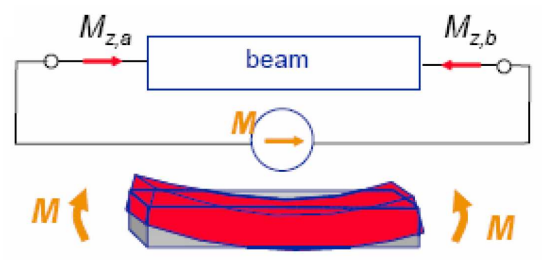

(c)

Fig. 1. Examples of mechanical nodal conventions. $\mathrm{F}$ and $\mathrm{M}$ are positive valued. (a) Beam in tension, $F_{x, a}=-F_{x, b}=-F$. (b) Beam accelerating in $\mathrm{x}$. $F_{x, a}=F_{x, b}=F$. (c) Moment bending beam with positive curvature in y. $M_{z, a}=-M_{z, b}=-M$, (Courtesy of [21]).

the electrical (electrostatic) energy domains [22]. Naturally, the design of reliable actuating techniques requires simple but realistic dynamic models of the device, either in input/output or in the state variable form. Accurate models lead towards optimal system design, better performance, better understanding of the device, short development time, and consequently, lower cost of the device. Furthermore, due to the compact layout, manufacturing tolerance, modeling errors, and environmental changes, MEMS are subjected to parasitics and parameter variations. In order to better guarantee their stability and a certain level of performance, one must take into account these factors in the design of MEMS control systems. This section reviews the models for system design (subsection II-A) and control subsection II-B associated with physical mechanisms, geometry/scaling issues or computational aspect for real-time control of MEMS with challenging issues in NEMS.

\section{A. Modeling for MEMS/NEMS design}

1) Reduced-order Models: In higher level MEMS/NEMS simulation applications, the computational complexity of getting an output for a given input from the model is simply too high. Thus, model reduction involves reducing the computational complexity of the model by reducing the number of parameters in the original model. If the original model is described by linear ordinary differential equations (ODE) then a typical approach is to write down the algebraic relation in the frequency domain. Reduced order models (ROM) are cheap in terms of memory and computational time and are needed to perform fast and efficient system-level composite circuit for MEMS on-chip development. For practical implementation of feedback control design, the models need to be finite-dimensional. In [24], a reduced nonlinear model was linearized at multiple operating points in order to design a PID-controller tuned via LMI-theory. For MEMS, truncated low-order models can be established this way, using a summation over only selected operating points. In the presence of significant nonlinearities, which often is the case for MEMS, the simple truncated models tend to be too imprecise. However, the technique can be enhanced, by combining structure of the model with finite element analysis a novel way to perform unknown parameters identification. New technique by combining the Taylor series expansion with the Arnoldi method to automatically develop reduced-order models for coupled energy domain nonlinear microelectromechanical devices is given in [25]. Model order reductions via Arnoldi algorithm applied directly to ANSYS finite element models has also been reported [26]. In this work, the authors adopt a micro accelerometer as an example to demonstrate the advantages of this approach. An electrostatically actuated fixed-fixed beam structure with squeeze-film damping effect was examined to illustrate the model-order reduction method in [27]. Compared with the linearized model, these works show that the reduced-order nonlinear models can capture the device dynamic behavior over a much larger range of MEMS operation but stability preservation is not guaranteed and has a low accuracy away from the expansion point. Based on differentiation of the discretized Finite Element (FE) equations for parameterization of MEMS macromodels (see, Figure 1) the authors in [21] computed the governing system matrices as well as high order derivatives (HOD) with regard to design parameters by means of Automatic Differentiation (AD). While the above formalisms were developed primarily for numerical simulations, the possibility to create nonlinear parameterized models based on Karhunen-Loeve decomposition is proposed in [23]. This reduced order model is cheap in terms of memory and computational time and compatible with fast and efficient system-level composite circuit for on-chip feedback control. In the presence of significant nonlinearities, which often is the case for MEMS, the simple linear model order reduction reported in this section tend to be rapidly imprecise due to the vast amount of possible expressions of nonlinearity. General approaches are formulated in the following section for updating the parameters of systems governed by multiphysics equations using advanced optimization techniques.

2) Macromodeling: Several computer algorithms based on 3-D Finite Element Analysis (FEA) have been coupled to 3D design tool to simulate MEMS, [28]. In order to alleviate the computational expense associated with the 3-D analyses, considerable efforts have been devoted to the development of reliable distributed reduced-order models (ROM) for MEMS, [21], [23]. As an illustration, model order reductions via the block Arnoldi algorithm with/without Taylor-series expansion directly to ANSYS finite element models have been proposed for MEMS accelerometers, [26], as well as electrostatically actuated fixed-fixed beam structure with squeeze-film damping effect, [29]. Furthermore, the authors in [30] demonstrated 


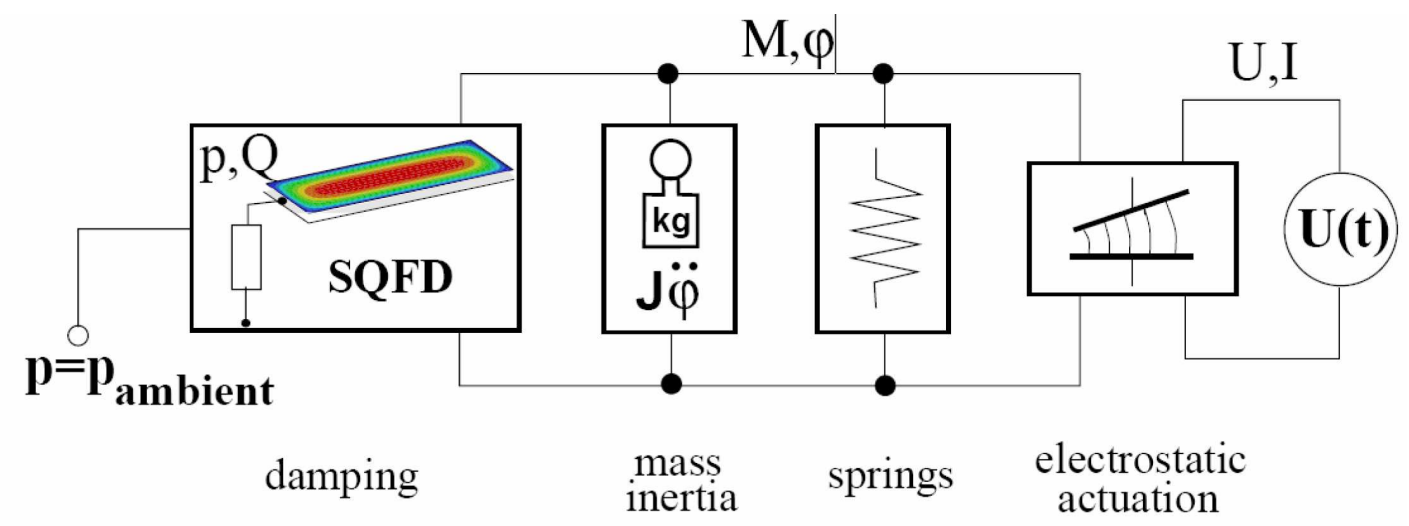

Fig. 2. System level model of an electrostatic torsional actuator. Damping is included as a mixed-level model, (Courtesy of [23]).

that the resulting ROM can capture the static/dynamic behaviors of the electrostatically actuated MEMS plate very well. Taking the analogy to electronic circuit design further, the next generation of MEMS system designers are starting to use composable MEMS models (macromodeling) [31] as the electrostatic torsional actuator shown in Fig. 2, [32]. It shows a mixed level damping approach where the torsional actuator dynamics is simulated by Navier-Stokes equationbased finite element modeling and the squeeze film damping by lumped-parameter modeling. The pioneering work in forming composable MEMS models is SUGAR from UC Berkeley [33], coventor ARCHITECT, [34], and NODAS from Carnegie Mellon, [35]. ARCHITECT and NODAS use Analog hardware description language (AHDL) descriptions, while SUGAR has its models written in MATLAB. In the later case, the performance of the tunneling MEMS sensor can be estimated and improved based on mechanical-level analysis by ANSYS and system-level analysis by MATLAB, [36]. A feedback control system with one zero and two poles has been synthesized, improving the dynamic range and the bandwidth of the closed-loop system (around $15 \mathrm{kHz}$ ).

Recently, MEMS design engineers developed a practical method that combines structure of the model with Finite Element Analysis (FEA) in novel way to perform system identification and identify the unknown parameters. The result was a lumped dynamical model of a MEMS device that can be used for the design of feedback control systems, [38]. In principle, any lumped-constant model can be described in this way, thus overcoming the most serious limitation of the equivalent-circuit modeling technique mentioned earlier. A likely reason for the popularity of this technique is that it makes it possible to simulate MEMS using ordinary circuit simulators. An another modeling alternative is to use functional entities representing nanodevices in an object-oriented fashion, termed macromodeling. Macromodeling procedure for coupled-domain MEMS devices with electrostatic and electrothermal effects have been widely presented. Numerical simulation of the dynamics using hybrid BEM/FEM (Boundary Element and Finite Element Method) approach was presented in, [39]. Hybrid analytical/numerical macromodels for the substructures with regular geometry were generated by analytical method and the ones with odd geometry by numerical method [40]. These techniques were tested on a generic MEMS device, a microtweezer. The nonlinear tunneling mechanism and electrostatic actuation were linearized using small-signal approximation. It must be noted that exporting macromodels for MEMS simulation requires the interfacing of various commercial tools for CAD (e.g., SolidWorks ${ }^{T M}$ ), FEA, simulation of electronic circuits (e.g., AHDL/VHDL language), control systems (e.g., Matlab/Simulink ${ }^{T M}$ ), multibody systems (e.g., ANSYS/Multiphysics ${ }^{T M}$ ) and also the microfabrication processes. There are definite drawbacks, the simulation of HDL models or models written in other high-level languages is usually considerably slower than the simulation of equivalent models built into the simulator. Furthermore, it is noteworthy to discuss macromodeling applicability in conjunction with MEMS control design since realtime feedback control issues are still unsolved.

3) Multiscale Models: The ability to design reliable MEMS/NEMS devices demand new simulation capabilities due to the length and time scaling effects at nanoscale [41]. Combination of classical microforces phenomena with quantum fields and molecular considerations become key issues to the point that thermal fluctuation influences the NEMS operation. Furthermore, the roles of surface and defects become more dominant. Finally, the behavior of materials at nanometer scale begins to be atomistic rather than continuous. Taken together, it gives rise to anomalous and often nonlinear effects, i.e., nanomechanics (Casimir effect, van der Waals, charges quantization), nano-optics (charge transfer), electrostatic-fluidics effects (dielectrophoresis, electro-welting, electroosmosis), nanomagnetics (paramagnetism), and so on. The challenge now faced by NEMS designers is to bridge the different scales to a more general framework, which has been coined as multiscale modeling [42]. Conceptually, two categories of multiscale simulations can be envisioned: both sequential and concurrent.

\section{(i) Sequential multiscale simulations}

The sequential methodology attempts to piece together a hierarchy of computational approaches in which large-scales models use the coarse-grained representations from more detailed smaller-scale models. In doing so, the simulations 
Physical Models

Features

Applications

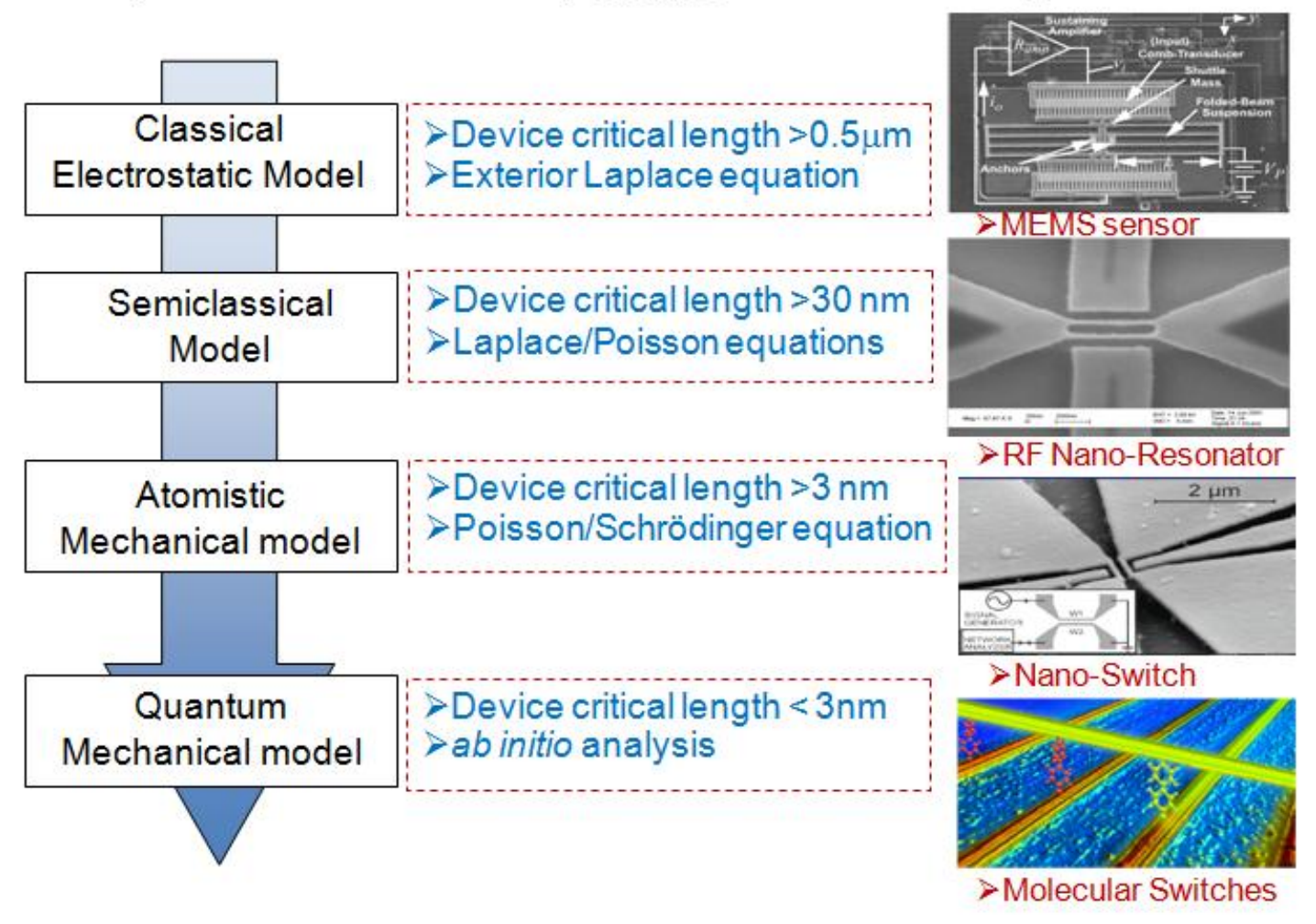

Fig. 3. A table showing the type of physical models, their features and the applications that are most suitable for respective modeling techniques (Courtesy of [37]).

are running independently of each other and a complete separation of both length and time scales are achieved [77], [73]. Some examples of sequential coupling show that to accurately model MEMS/NEMS devices at least three lengthscales need to be explored: mesoscopic at the package level; microscopic at the actuator/sensor level and nanoscopic at the material level. Reliability of packaged polysilicon microelectromechanical systems involves the computational study of environmental effects to predict the long-term performance of MEMS packages at mesoscopic and microscopic length scales. The authors in [72] present a multiscale finite element modeling (FEM) approach coupled to Monte-Carlo (MC) analysis for MEMS failure prediction. In a same way, a predictive-science-based multiscale modeling and simulation platform is proposed in [78] to predict material performance issues, such as radiation, thermo-mechanical cycling and damage and fracture due to shocks. The computational coupling of the atomic-scale description of nanomaterials (Molecular Dynamics (MD) simulation) to microscale actuators designs (traditional finite difference (FDM) or finite-element modeling (FEM)) pose severe challenges. MD simulation cannot simulate the whole systems due to its prohibitive computational cost, whereas continuum FEM/BEM scales poorly with system size and only approximately account for effects at material interfaces. To remedy these inadequacies, several authors coupled FDM/BEM simulations to MD models whose underlying physics are derived from nanomechanics theory [51], [79], [80], nanoelectronic structure theory [59], nanofluidics theory [81], and molecular biology [74]. In overall, the sequential multiscale model showed good qualitative agreement with the experimental measurements but requires more refinement to achieve good quantitative agreement.

\section{(ii) Concurrent multiscale simulations}

The concurrent multiscale approach attempt to link methods appropriate at each scale together in a combined model, where the different scales of the system are considered concurrently and communicate with a hand-shake procedure. The literature contains numerous methods of concurrent coupling; (i) the 
TABLE I

COMPARISON OF MODELING AND SIMULATION APPROACHES FOR MEMS AND NEMS DESIGN.

\begin{tabular}{|c|c|c|c|c|c|c|}
\hline Length scale & Modeling & Key Ref. & Time scale & $\begin{array}{l}\text { Computational } \\
\text { complexity }(\star)\end{array}$ & $\begin{array}{c}\text { Computational } \\
\text { error }(\%)\end{array}$ & Modeling level \\
\hline \multirow[t]{4}{*}{$\begin{array}{l}\text { Macroscopic } \\
L \geq 10 \mu m\end{array}$} & $\begin{array}{c}\text { Physical models } \\
\text { Classical Physics } \\
\\
\text { Dynamical State-Space model } \\
\text { Lumped Dynamical model } \\
\text { High-Order Derivatives model }\end{array}$ & $\begin{array}{c}{[43],[44],[45]} \\
{[46],[47],[48]} \\
{[49],[50],[51]} \\
\\
{[52],[53],[54]} \\
{[55],[56]}\end{array}$ & $1 s \leq t \leq 10 s$ & $O\left(n^{2}\right)$ & $\sim 10-30 \%$ & System-level \\
\hline & $\begin{array}{l}\text { Composite circuit macromodels } \\
\text { VHDL/AHDL language } \\
\text { Mixed-level model }\end{array}$ & $\begin{array}{l}{[33],[34],[35]} \\
{[40],[39],[57]}\end{array}$ & & $O\left(n^{2}\right)$ & $\sim 20 \%$ & System-level \\
\hline & $\begin{array}{c}\text { Continuиm Models } \\
\text { Finite Element Methods } \\
\text { Boundary Element Methods }\end{array}$ & $\begin{array}{l}{[58],[21]} \\
{[42],[59]}\end{array}$ & & $O\left(n^{3}\right)$ & $\sim 15 \%$ & MEMS part-level \\
\hline & $\begin{array}{c}\text { Model Order Reduction } \\
\text { Krylov algorithms } \\
\text { Arnoldi algorithms }\end{array}$ & $\begin{array}{c}{[23],[60]} \\
{[25],[29],[61]}\end{array}$ & & $O\left(n^{2}\right)$ & $\sim 5-10 \%$ & MEMS part-level \\
\hline $\begin{array}{c}\text { Mesoscopic } \\
100 \mathrm{~nm} \leq l \leq 1 \mu \mathrm{m}\end{array}$ & $\begin{array}{c}\text { Stochastic Methods } \\
\text { Direct Monte Carlo Methods } \\
\text { Kinetic Monte Carlo }\end{array}$ & $\begin{array}{l}{[62]} \\
{[63]}\end{array}$ & $1 \mu \mathrm{s} \leq t \leq 1 \mathrm{~ms}$ & $O\left(n^{3}\right)$ & $\sim 25 \%$ & $\begin{array}{l}\text { Functional-level } \\
\text { Functional-level }\end{array}$ \\
\hline $\begin{array}{c}\text { Molecular } \\
10 \mathrm{~nm} \leq l \leq 100 \mathrm{~nm}\end{array}$ & $\begin{array}{c}\text { Molecular Dynamics } \\
\text { Tight-Binding Molecular Dynamics } \\
\text { Coarse-Grained Molecular Dynamics } \\
\text { Stochastic Dynamics }\end{array}$ & $\begin{array}{c}{[64],[65],[66]} \\
{[67]} \\
{[68]} \\
{[69]}\end{array}$ & $1 n s \leq t \leq 1 \mu s$ & $O\left(n^{4}\right)$ & $\sim 20-30 \%$ & $\begin{array}{l}\text { Functional-level } \\
\text { Functional-level } \\
\text { Functional-level } \\
\text { Functional-level }\end{array}$ \\
\hline $\begin{array}{c}\text { Atomistic } \\
1 \stackrel{A}{\leq} \leq \leq 1 \mathrm{~nm}\end{array}$ & $\begin{array}{l}\text { Density Functional Theory } \\
\text { Hartree-Fock Approximations }\end{array}$ & $\begin{array}{l}{[70]} \\
{[67]}\end{array}$ & $1 p s \leq t \leq 1 n s$ & $O\left(n^{5}\right)$ & $\sim 15 \%$ & $\begin{array}{l}\text { Atomic-level } \\
\text { Atomic-level }\end{array}$ \\
\hline $\begin{array}{c}\text { Multiscale } \\
1 \stackrel{A}{\leq} l \leq 100 \mu m\end{array}$ & $\begin{array}{l}\text { Continuum/MD coupled models } \\
\text { FEM/CGMD coupled models } \\
\text { FEM/MC coupled models } \\
\text { continuum/MD/QM coupled models }\end{array}$ & $\begin{array}{c}{[71]} \\
{[68]} \\
{[72][73],[74]} \\
{[75],[76]}\end{array}$ & $1 p s \leq t \leq 10 s$ & $O\left(n^{5}\right)$ & $\sim 5-10 \%$ & $\begin{array}{l}\text { System-level } \\
\text { MEMS part-level } \\
\text { System-level } \\
\text { System-level }\end{array}$ \\
\hline
\end{tabular}

$\star$ where $n$ is the number of features in environment.

combined finite element atomistic method (FEAt), (ii) the material point method (MPM), (iii) the local quasicontinuum method (QC), (iv) the bridging scale method, (v) the atomicscale finite element method (AFEM), and (vi) coarse grained molecular dynamics (CGMD) [82], [41]. Molecular dynamics simulations are commonly used to investigate size-dependence of the elastic properties of the nano-scale silicon cantilevers [66]. It reveals that continuum mechanics modeling can still be used on nanoscale structures provided that the dependence of elastic constants on dimensional scaling is accounted for. At a larger scale Coarse-Grained Molecular Dynamics (CGMD) modeling have been developed [68] to describe the behavior of the mechanical components of MEMS down to the atomic scale. It builds a generalized finite element formalism from the underlying atomistic physics in order to ensure a smooth coupling between regions governed by different length scales. Various electrostatic models namely: the classical conductor model [71], the semiclassical model [83], and the quantum-mechanical model [51], are being used for electrostatic analysis of NEMS at various length scales. The design methodology facilitates, under restricted conditions, the insertion of quantum corrections to nano-scale device models, during simulation. In the case of NEMS-based electrostatic actuation, Figure 3 shows the evolution of modeling theory w.r.t. device length scale : from classical continuum models to atomistic quantum mechanical models. In [37], a multiscale method, seamlessly combining semiclassical, effective-mass Schrödinger, and Tight-Binding Theories (TBT), is proposed for electrostatic analysis of silicon nanoelectromechanical systems. In [84], an integrated modeling methodology for nano-scale electronic devices has been proposed. This methodology includes domain-oriented approximations from ab-initio modeling and the selection of quantum mechanical compact models that can be integrated with basic electronic circuit or non-electronic lumped-element models. Finally, molecular dynamics (MD) and ab-initio quantum mechanics $(\mathrm{QM})$ coupled to virtual reality (VR) techniques have been developed in [75], [76] for the prototyping of biological NEMS. The operator can design and characterize through molecular dynamics simulation, the behavior of bio-nanorobotic components and structures through 3-D visualization. In these works, the 
nonlinear continuum elastic theory, with material properties extracted from MD simulations, is combined with either the classical, semiclassical, or the quantum-mechanical electrostatic model and the continuum theory for the van der Waals energy domain to compute the self-consistent electromechanical behavior of biological NEMS. From the point of view of control, the concurrent coupling between the mechanical and the electrical energy domains at nanoscale necessitates a proper understanding of relevant physical theories for NEMS feedback control [85]. Actually, carbon nanotube-based NEMS devices (nanoswitch, nanotweezers) are actuated using analytical energy-based methods modeling (electrical capacitance model including van der Waals forces as well as finite kinematics) to predict the structural behavior and instability of the on/off states of the nanoswitch, or the open/close states of nanotweezers [42]. Recently, the influence of control parameters on the stationary oscillations of carbon nanotube-based oscillators via molecular dynamics simulations have been conducted [64]. The control of oscillator motion in the case of considerable fluctuations through the control force has been rendered possible. The methodologies reported here are completely general and as such are expected to be useful in the optimal control of nanotube-based NEMS devices.

4) Discussion: Table 1 gives a comparison table of various modeling technologies with its pros and cons. Methods used for simulation of several properties of MEMS/NEMS differ in their level of accuracy and in the computation time necessary to perform such calculations. Accordingly, the time scales that each of these methods can handle can be from a single total energy for the most accurate calculations, to picoseconds for $a b$-initio molecular dynamics simulations, and up to seconds for classical physics. The MEMS/NEMS design optimization requires a tradeoff between very accurate and computationally expensive descriptions of atomic nanomaterial phenomena and coarse system description avoiding prohibitively large computations. Classical continuum theories which are based on continuum assumptions are efficient and accurate at mesoscopic scale, but they may not be directly applicable for NEMS of nanoscale features. Atomistic simulation methods such as first-principles quantum-mechanical methods, molecular dynamics and Monte Carlo simulations are generally accurate for the mechanical analysis of nanostructures. However, the extremely high computational cost prohibits the application of the atomistic methods at the MEMS/NEMS device level. The unified multiscale approach can retain the accuracy that the individual approaches provide in their respective scales and provides a realistic modeling at the system-, MEMS part-, functional- and atomic-level.

\section{B. Modeling for MEMS/NEMS control}

1) Physical Models: Physicals methods for determining lumped dynamical models of thermal, piezoelectric, magnetic or electrostatic MEMS and NEMS devices for purposes of feedback control have been studied extensively in literature. Current modeling works are mainly focused on the empirical responses of the system dynamics, black-box models, as a practical model for real-time control, but offer minimal insight into the governing equations. System identification based on measured sets of input and output data obtained from exciting the system with pseudo random binary data (PRBS) gives a good fit to the measured data. The MEMS dynamics are dominated mainly by the first mode which can be accurately modeled by a mass-spring-damper second order-model, e.g. piezoelectric MEMS scanner [45], polymer MEMS actuators [48], piezoelectric microrobot-on-chip [86] and electrostatic MEMS vibrational gyroscope [87]. However, when the number of parameters grows, it becomes more difficult to span the complete parameter space, since each parameter lets the number of possible variations grow in an exponential way. As example, the fast dynamics of MEMS systems require higherorder models leading to complicated model-based controllers. As a more detailed approach, the gray-box models are developed for determining lumped dynamical models of MEMS devices, [52], [53], [54], for purposes of feedback control. A model consisting of millions of equations (e.g., a FEM model) is surely more difficult to handle and takes more time to solve than an analytic expression based on a simplified gray-box model. In [88], the authors determined a dynamical statespace model for control of thermal MEMS devices. The importance of temperature-dependent parameters was emphasized for dynamical modeling for purposes of feedback control. In [56], a computationally efficient model was developed for investigating the dynamics of the voltage-driven MEMS device embedded in a dielectric fluid. However, these models were partly based on physical principles while also relying on empirical results to define complex physical processes. Due to the compact layout [89], manufacturing tolerance [90], modeling errors [22], and environmental changes (e.g., adhesive surface interactions, and scale dependent material and thermal properties) [91], MEMS devices are subjected to parasitics and parameter variations. In order to better guarantee their stability and a certain level of performance, one must take into account these factors in the design of MEMS control systems. In the most complex form, white-box models with partial differential equations (PDEs), e.g., [55],[56], attempt to explain the underlying physics for the sensing and actuation responses of MEMS and NEMS. Nonlinear models based on finite-difference discretization of MEMS structures, e.g. lateral electrostatically-actuated DC-contact MEMS [53], and applying boundary conditions have been recently solved using a Gauss-Seidel relaxation iteration scheme. More efficiently and equally accurate during circuit simulation than PDEs, Volterra-series-based modeling describes the frequency dependence (e.g., the mechanical resonance) in combination with the nonlinear behavior of the MEMS variable capacitor [92]. As the complexity of such models involves model reduction techniques, there is always a tradeoff between accuracy of the model or possible range of application.

2) Advanced Modeling Algorithms: Recently, black-box advanced modeling algorithms of non-electronic parts has been introduced in MEMS modeling, so enabling radically faster simulation without concurrent algorithms and parallel computation, e.g. artificial neural networks (ANN), genetic algorithm 
(GA) optimization, model prediction (MP), or fuzzy logic algorithms (FL). In [93], a lumped model of the capacitive transducer, being the part of a MEMS capacitive pressure sensing system, was created using an ANN. The ANNs here are considered universal approximators, convenient for blackbox device modeling. A general approach was formulated in [30] for updating the parameters of systems governed by multiphysics equations using an optimization technique based on Genetic Algorithms (GAs). This approach was demonstrated on a MEMS micromirror which was governed by both structural and electrostatic physics. For systems with fast dynamics such as those in MEMS, a hardware embedded realtime implementation of model predictive control (MPC) has been investigated in [94]. The results show that MPC would be an appropriate controller implementation since the size and the application precludes the use of a dedicated computer. Finally, a method for reliability prediction was presented in [95], based on a combined fuzzy-logic and physics-of-failure approach. The specific case of a MEMS Fabry-Perot interferometer was analyzed and the failure rate estimations are discussed. Similar fuzzy logic control algorithms have been applied to optimally charge the microbattery of on-board MEMS sensors [96]. Recent manufacturing advances have opened the path for the fabrication of micromechanical devices and electronic subsystems under the same manufacturing and packaging process, thereby opening the path for the use of advanced modeling algorithms towards systems-on-chip applications.

\section{Control Schemes}

Presence of sensor dynamics, fast high-frequency system dynamics and extremely sensitive system parameters make the control of MEMS devices a complex task. Over the years, researchers all over the world have come up with feasible control algorithms for MEMS devices. Based on these results, control techniques for MEMS can be grouped under three broad classes viz: open-loop control, open-loop control with input pre-shaping and closed-loop control, [97]. The choice of the control technique depends on various factors such as application, needed electronic circuitry, device dynamics, space constraints and sensor availability / implementation. The following sub-sections will review the various control strategies mentioned earlier. The section will close with a review of the on-chip control strategies that have been implemented by researchers so far, (Subsection III-D).

\section{A. Open-loop control}

During the infancy stages of MEMS technology, most MEMS devices were controlled in open-loop by applying very simple control inputs. This was mainly due to the relatively high speed of actuation as well as the inability of the then existing sensor technologies to procure noise-free sensory information that was unbiased by the sensor dynamics. Though advances in sensor and actuator technologies have further pushed the boundaries of accurate sensing at the micro- and nano-levels, successful integration of these sensors in MEMS remains an ongoing challenge, [20]. Recent advances have resulted in improving the traditional MEMS designs to achieve better dynamic performance under open-loop actuations, [27]. Open-loop control for large deflection electrostatic actuators was reported in [17]. In this paper the authors incorporated significant design improvements to the existing comb-drives designs [98], [99]. These improvements included reducing the actuator area by half, redesigning comb-teeth and suspensions to reduce side instability and using a launch and capture actuation scheme. MEMS deformable mirrors have been popularly controlled in open-loop, [100]. The open-loop scheme delivered accurate tracking to within 3\% error. Wavelengthdivision multiplexed (WDM) routers with analog micromirror arrays were shown to operate in open-loop with excellent repeatability and stability, [101]. High repeatability and longterm stability of a MEMS wavelength selector switch in openloop operation was demonstrated in [102], though it lacked a 100\% add / drop functionality. A low-drift micromirror in open-loop control was demonstrated in [103]. Open-loop control of a MEMS deformable mirror using a nonlinearly constrained quadratic optimization approach has also shown improvements in performance, [104]. In this case, with an apriori knowledge about the aberrations in the target waveform, a quasi-steady state control was obtained. Though simulated results reportedly showed improved performance, practical implementation of this rigorously mathematical technique may be quite challenging. Recently, MEMS actuator designs are being modified to give better open-loop performance, [105]. An improved modeling technique that resulted in open-loop control of a tunneling accelerometer for very high resolution acceleration measurement was reported in [106]. In this case the tunnelling accelerometer was modeled based on a clamped micro-circular plate with a tunneling tip and the classic Kirchhoff thin plate theory was used for deriving the governing equations. A new hardware platform for tuning a MEMS based gyroscope in open-loop by measuring the frequency response of the device was reported in [107]. These platforms tuned the gyroscopes based on an evolutionary computational technique that improved the sensitivity of the gyroscopes and also enabled closed-loop operation. An open-loop technique to address the Sagnac effect in a fiber-optic gyroscope based on MEMS/NEMS fabrication has also been proposed in [24].

As problems such as inherent system nonlinearity, induced vibrations and effects such as stiction and friction cannot be completely addressed using open-loop control in many MEMS devices, input pre-shaping was seen as the next logical step in MEMS control.

\section{B. Open-loop control with input pre-shaping}

This technique relies on the fact that the static and dynamic behavior of many MEMS devices can be accurately modeled and in most cases, linearized. In this technique, the input signals are made more complex by shaping them in a way such that the adverse effects of the system dynamics are minimized (Ex: Bandlimiting the trajectory signal such that the natural frequencies/system resonances were not excited), [109]. For input pre-shaping, an accurate dynamic model of the system is of paramount importance, if any performance improvement is expected. An open-loop method that predicted 


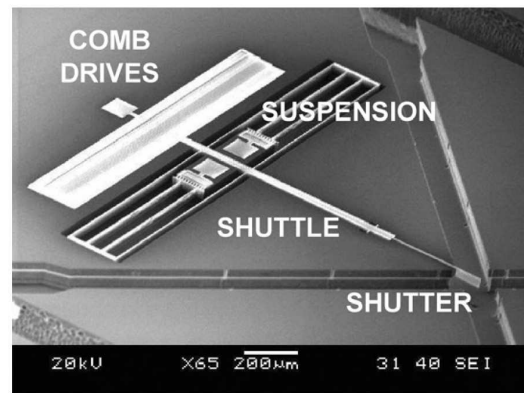

(a)

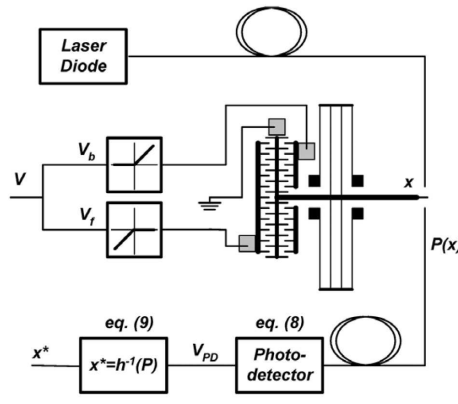

(b)

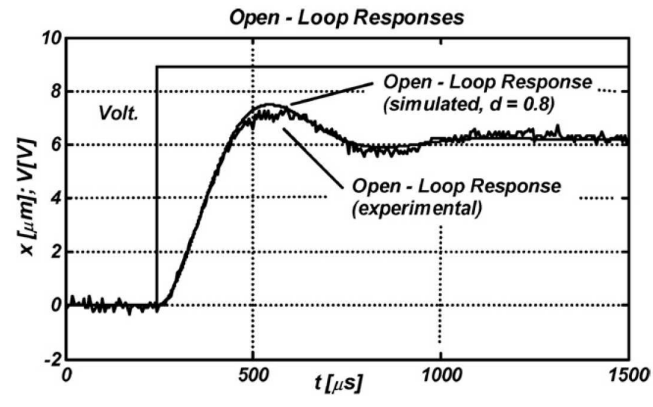

(c)

Fig. 4. (a) Scanning electron micrograph of a MEMS variable optical attenuator (VOA). (b) Schematic of the experimental setup of the VOA(c) Open-loop step responses for the simulated model and the actual VOA, (Courtesy of [97]).

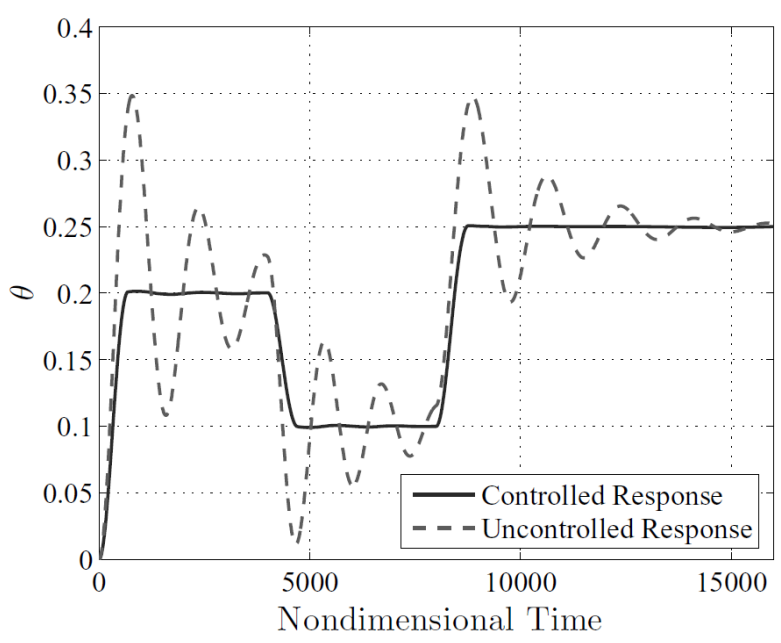

(a)

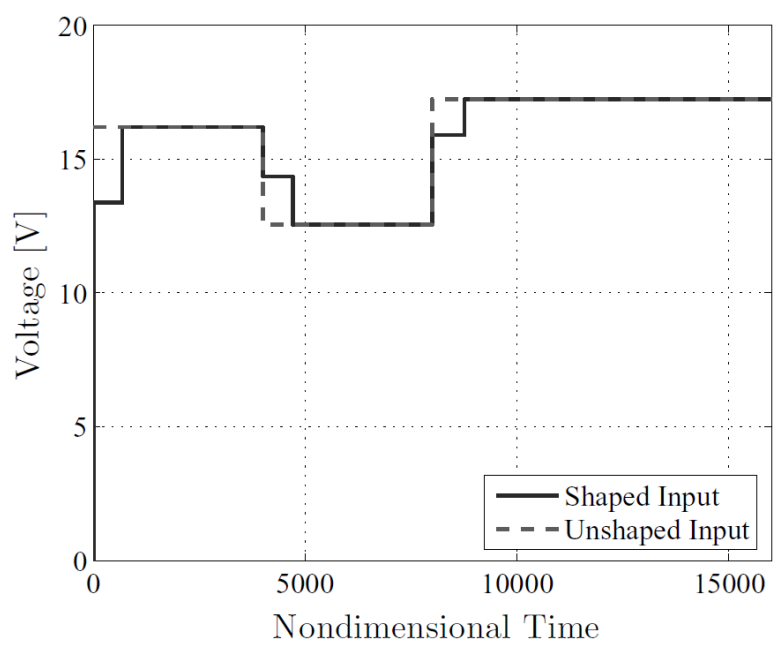

(b)

Fig. 5. (a) Controlled (using shaped signal - solid) and uncontrolled (using standard step commands - dashed) tilt angle responses achieved by the MEMS micromirror. (b) Corresponding shaped (solid) and unshaped (dashed) actuation voltage signals, (Courtesy of [108]).

control voltages generating prescribed surface shapes on a MEMS deformable mirror was given in [110]. In this work, an analytic elastic model was used for the mirror membrane and an empirical electromechanical model was used for the actuator dynamics. Open-loop control with input pre-shaping has also been applied to control oscillations of MEMS based gyroscopes. For accurate angular rate measurement, the drive mode oscillation amplitude of the second mass has to be kept constant. By approximating the gyroscope by a lumped massspring-damper model and applying pre-computed actuation voltages, the oscillation amplitude can be kept constant as shown in , [111]. For MEMS devices that involve multiple moving parts, such as MEMS mirror arrays, a feed-forward based control has been patented, [112]. This patent was specific to MEMS based, optical mirror arrays where motion of an active mirror has an aerodynamically disturbing effect on the neighboring static mirrors in the array. In this technique, feed-forward control signals with a normalized profile that minimized the aerodynamic coupling between the static mirrors were employed to cancel the induced disturbances. Feedforward control of a MEMS optical switch was reported in [113]. In this implementation, feed-forward was used to force the switch to reach the desired position in a fast and accurate manner with minimal overshoot.

Very recently, a patent was awarded for a input shaping actuation technique for MEMS devices, [114]. In this patent, a filtered voltage signal shaping technique has been demonstrated. This scheme is mainly useful in conjunction with MEMS devices that have micro-cantilevers and other vibrating elements whose natural resonances are minimally damped. The patent is based on results obtained in [115] by actuating a two-axis gimbal-less scanner using the openloop with input pre-shaping technique presented in the patent. Filtering the input voltages may not always be feasible as it adds to either the system or the computation cost. Additionally, sub-optimal filtering may lead to unachievable slew-rates and supply saturation. It is the property of electrostatic MEMS actuators to generate a residual charge in their insulating layer that results in sticking of the electrode and increases response time. To prevent this sticking of electrostatic MEMS actuators and generate fast actuator response, an input pre-shaping technique was described in [116]. The patented technique of Input 
Shaping was demonstrated to potentially nullify unwanted vibrations in MEMS devices such as MEMS optical switches in [117]. A similar technique was used in [108], to drive a micromirror to a desired tilt angle without residual vibrations, see Figure 5. The key advance in this input shaping technique was the inclusion of nonlinear system behavior, thus making it suitable for application in conjunction with a wide range of MEMS systems.

The inherent reliance of the input-preshaping technique on an accurate system model as well as a-priori information of the system behaviour limits the adaptability and robustness that can be built into this particular control technique. Finally, the combined advances in MEMS technology, sensor and actuator designs, system analysis tools and the ever-present demand to push the boundaries of performance in terms of speed, reliability and accuracy have led to the MEMS system be controlled by employing complicated closed-loop strategies [118].

\section{Closed-loop control}

Standard control techniques such as PID have been implemented on MEMS devices manufactured in bulk, such as MEMS based sensors and switches, [120], [121]. MEMS based sensors have been using closed-loop control for quite some time. Hitachi demonstrated a MEMS based closed-loop silicon accelerometer more than a decade ago, [122]. Closed-loop control was used for a MEMS micro-cantilever based pressure sensor [123]. In this application, an electromagnetic beam integrated onto a standard silicon pressure sensor diaphragm was driven to resonance using closed-loop control. As the diaphragm deflects under pressure, the stress in the beam caused a change in its resonant frequency. This change was found to be a highly sensitive measure of pressure [124]. This device offered wide dynamic range, high sensitivity, and high stability. It was also easy to be interfaced with digital compensation circuitry. Another successful application of closed-loop control in MEMS was reported in [125], where improving measurement accuracy was the main objective. Feedback control has been employed to accurately regulate the gap distance in an electrostatic MEMS based FabryPerot interferometer, [126]. In this implementation, a feedback circuit capable of sensing the property of the active device and providing an electrical stop when the minimum separation distance was achieved was integrated.

Closed-loop feedback control has been a common strategy to correct for machining imperfections in MEMS based gyroscopes. [127], [111] proposed active nonlinear and adaptive drive control approaches to compensate for errors due to device imperfections. Closed-loop tuning of a MEMS based gyroscope was reported in [107]. A custom-built integrated circuit that manages the signal filtering and provides real-time control for the JPL-Boeing manufactured MEMS based gyroscopes was reported in [128]. This technique used an ASIC that enabled the gyroscope to reject vibration disturbances and damped the transfer function by almost $40 \mathrm{~dB}$. A US Patent for an application specific integrated circuit capable of exciting a selected gyroscope mode, induce damping and demodulate the signal containing the angular rate information to in-phase and quadrature components was issued, [129]. This circuit featured attractive properties such as low power consumption as well as ease of sensor integration. A dual-stage control algorithm that provided on-site identification of imperfections based on the dynamic response of the device and compensated for it using nonlinear electrostatic parallel plate actuators was proposed in [130]. In this paper, the authors first showed that using feedback alone to compensate for large structural imperfections (to the tune of $10 \%$ ) would seriously compromise the device performance. Consequently they successfully employed a feedforward control loop to reduce large imperfections and combined it with a feedback loop to compensate for the device non-idealities and perturbations. [131] presented a novel architecture for the digital control of MEMS based gyros. Digital control was also proposed for performance optimization of a MEMS based gyroscope, [132]. In general digital control was shown to offer more flexibility in terms of algorithms as well as control parameters. FPGAs used in these implementations significantly speed up the development process due to their ease of programmability. Cross-coupling and fabrication imperfections are the major performance limiting factors in MEMS based gyroscopes. Adaptive control based on velocity estimation has shown promise in alleviating these problems and improve the overall performance of the gyroscope by achieving larger operational bandwidth, eliminating zero-rate output, enabling self-calibration and deeming the gyroscope highly robust to parameter variations, [133], [134]. To further improve the gyroscope performance by accurately estimating the unknown angular velocity, sliding mode control has also been formulated, [135], [136]. These investigations proved that though computationally intensive, both these nonlinear approaches could significantly enhance the device performance. Furthermore, they also showed that sliding mode control controller of the vibrating proof mass resulted in a better estimate of the unknown angular velocity than that of the model reference adaptive feedback controller. An active disturbance rejection control scheme was proposed recently to address issues such as mechanical-thermal noise, parameter variations, quadrature errors and the mismatch of natural frequencies between two axes, [137]. In this work the two main control problems addressed were the vibrating modes of the gyroscope axes and the time-varying rotation rate estimation. These major issues can also be alleviated using an adaptive control method based on Lyapunov functions, as demonstrated in [138]. A discrete time observer-based adaptive control algorithm for improved angular rate estimates has also been reported, [139].

Performance enhancement for a probe-based data storage system was reported in [140]. In this paper, the authors proposed a position control system that resulted in accurate positioning of the micro-cantilever probe over a particular sector of the data storage disc. Positive Position Feedback (PPF) control was implemented successfully to provide active damping to a piezoelectric MEMS acoustic sensor, [141]. A detailed comparison between open- and closed-loop control of a MEMS electrostatic comb drive was given in [38]. Model Reference Adaptive Control (MRAC) technique was 


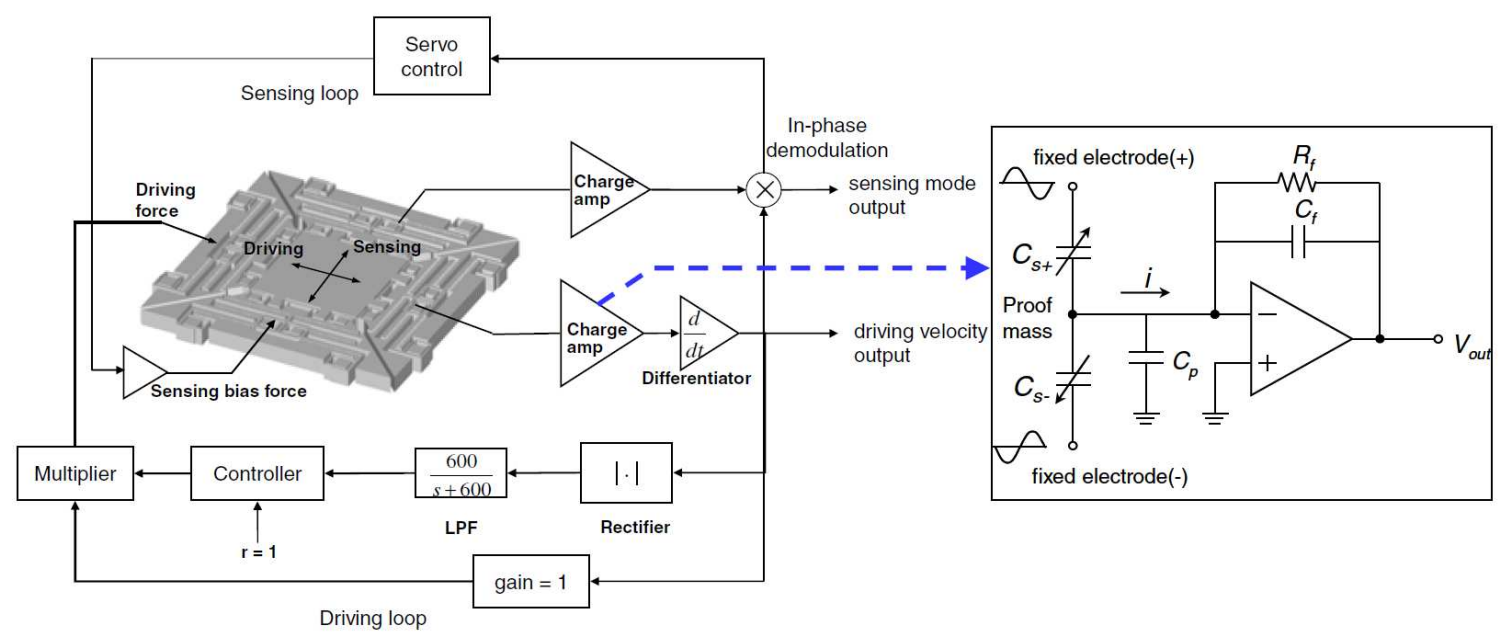

(a) Implementation of the Adaptive Gain Control (AGC) feedback system for the velocity-controlled gyroscope.
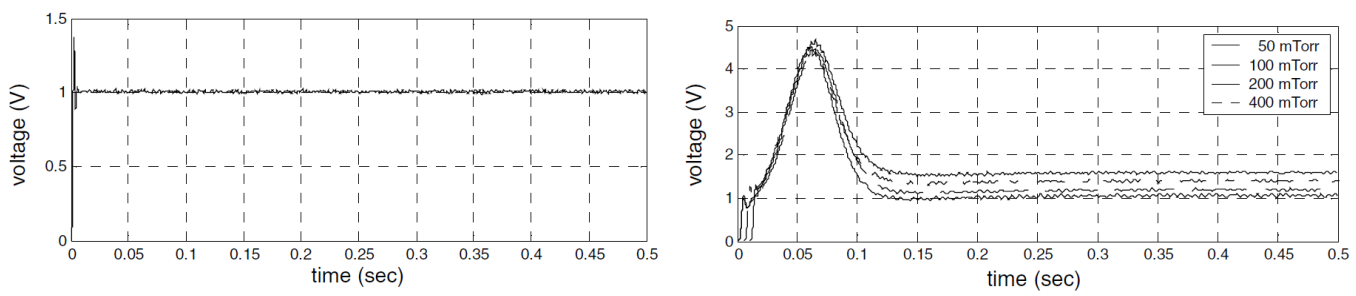

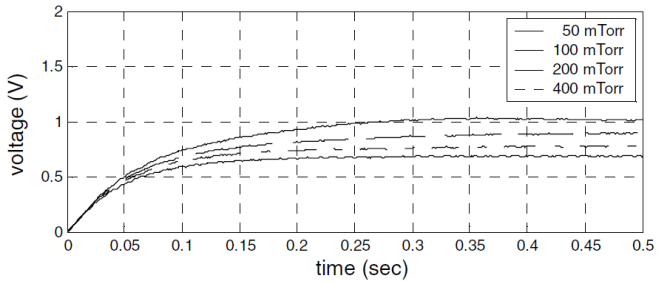

(a)

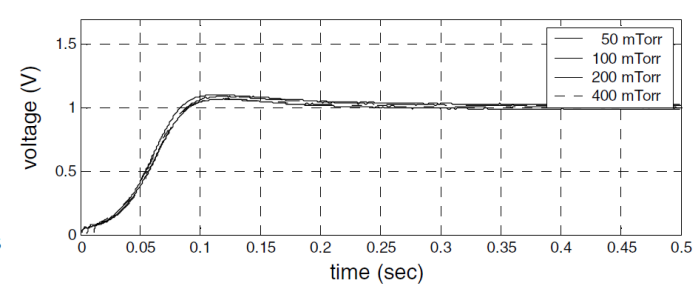

(b)

(b) Magnitude of the driving signal and envelope of the associated velocity signal under various vacuum conditions for open-loop (a) and closed-loop (b), (Courtesy of [119]).

formulated for tracking control of MEMS based comb resonators, [142]. A real-time implementation of this technique demonstrated its ability to handle multiple uncertainties in device parameters that occur due to machining imperfections. In [113], a linear feedback controller was used to shape the system dynamics in a MEMS optical switch, resulting in fast switching operation. Nonlinear control was also used in manipulating MEMS based mirrors for high tilt and pointing accuracy, [143]. In this application, digital implementation of a full-state feedback was carried out resulting in a substantial increase in the mirror's angular operation range and a reduction in the long-term angular noise. Nonlinear sliding mode control applied to controlling the position of a lateral comb resonator has been simulated in [144]. A cooperative angle control scheme to reduce the output stable control time in MEMS optical switches was proposed in [145]. In one of the novel applications, feedback control has been employed to provide accurate input gains and implement signal up- modulation to a MEMS based high-performance operational amplifier, [146]. In this application, the input stage of the operational amplifier is a MEMS based variable capacitor that converts low-frequency input voltages to high-frequency $\mathrm{AC}$ currents, resulting in reduced offsets and low-frequency noise.

In most closed-loop control of MEMS devices, the control loop was implemented using external circuitry and computing facilities. In many cases, even the sensors were independent and not an integral part of the MEMS device. With improved fabrication methods, component densities on a chip have increased drastically and on-board sensors and power sources have become the norm, [147], [148], [149], [150]. Thus, the system-on-chip concept with on-chip control is now gaining popularity, [151], [152], [153].

\section{On-chip feedback control: The current trend}

The main advantages of on-chip feedback are: (1) improved linearity, (2) improved signal-to-noise ratio and (3) improved 


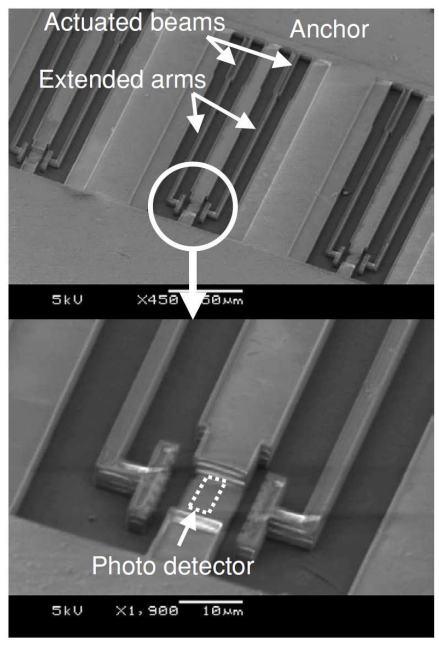

(c)

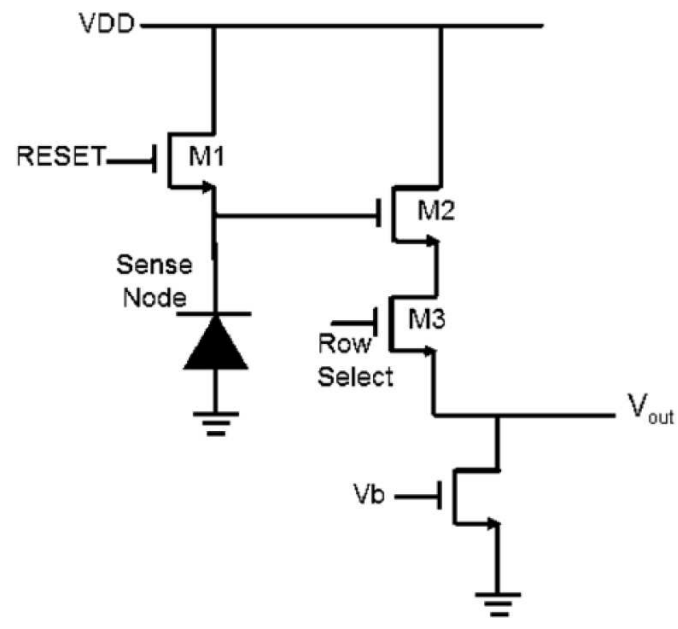

(d)

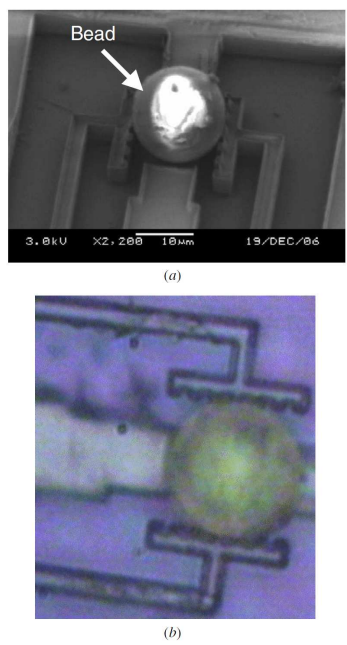

(e)

Fig. 6. (a) Scanning electron micrograph of the released microgrippers showing the on-chip photo detectors placed beneath the gripping sites. (b) Schematic of the photo-detector circuit (c) Gripping of a polystyrene bead: before (top); after (bottom), (Courtesy of [154]).

accuracy due to ease of compensation for interferences and system dynamics. The vast improvements in MEMS design and fabrication have led to real-time on-chip feedback control being the current thrust of many research endeavors. One of the main control issues for on-chip applications is power generation. Electrical power is needed for the actuation as well as sensory systems used in MEMS. Generating this power efficiently with-in the given space constraints of a MEMS chip, without causing insulation, dynamics or interference problems is a major concern and research focus. Some on-chip power sources have been reported and various power generation schemes are being investigated, [149], [148].

Microfluidics is an area where real-time feedback has been applied successfully, [155]. Precise handling of microfluidics in continuous-flow by using a flow sensor to monitor and onchip pumps with feedback control to regulate the flowrate was presented in [156]. Electrowetting-on-dielectric (EWOD) has been proposed as a method of actuation for on-chip droplet generation [157]. Due to its compatibility with miniaturization, simple device configuration and fabrication, capacity to generate large forces at microscale, and low energy consumption EWOD has gained popularity in microfluidic applications. To monitor droplet volume and control applied voltages for onchip droplet generation of constant volumes real-time feedback control was necessary. A successful feedback strategy that resulted in automated volume-controlled on-chip generation of droplets was reported in [158]. To account for the uncertainties during droplet separation, an improved feedback scheme was proposed in [159]. In this work the authors combined voltage modulation, capacitance sensing and a discrete-time PID controller to obtain significant improvements in droplet volume uniformity when compared to open-loop and standard closed-loop techniques.

On-chip control has also been applied to MEMS based highspeed synchronous micromotors, [22]. In this work, on-chip
VLSI drivers are used for various signal processing, filtering, computing, interfacing and amplification tasks and the control of micromotors is achieved by applying the proper phase voltages to the micromotor windings. The control technique also incorporates robust tracking and disturbance rejection. Nonlinear control of electrostatic MEMS using a novel integrated charge and position sensor was reported in [160]. This technique resulted in full gap operation and improved transient performance. The control technique showed on-chip implementation potential as it could use the local integrated circuit components and the required sensor was easy to fabricate, did not increase device footprint and had negligible effect on the device dynamics. The design of an on-chip CMOS potentiostat was reported recently, [161]. The potentiostat was mainly developed for controlling the volume of conjugated polymer film used in microactuators. This on-chip mechanism was proposed for controlling microactuators used in cell capture microsystems.

With the advent of nano-electromechanical systems (NEMS), on-chip sensor technologies are being revolutionized, [154], [162]. As a result, the future is bright and holds exciting prospects for on-chip control of MEMS devices.

\section{A LOOK IN TO THE FUTURE}

Nanometer scale actuators and sensors that can provide motion and measurement with nanometer-order resolution will enable new industrial applications in which only a few atoms or molecules are measured, transported, or processed. The design of molecular systems in which controlled linear and rotary motion can be achieved under the influence of an external signal is a major endeavor toward future nanoscale machinery. New and exciting phenomena have been observed in multi-walled carbon nanotubes (MWNTs), including field emission [163], quantum conductance [70] or constant-force nanosprings [164]. Based on these effects, 
nanoscale linear servomotors with integrated position sensing have been investigated from experimental, theoretical, and design perspectives. Fennimore was the first to show an electromechanical actuator based on MWNTs [165]. Actuation experiments have demonstrated the feasibility of a prismatic nanoservomotor with integrated position sensing based on field emission [166]. The complete extension of the inner core is observed and the electrostatic force is calibrated to be tens of nano-Newtons for individual nanotubes $16.5 \mathrm{nN}$ under a 30$\mathrm{V}$ bias. Such nanotube actuators have mainly been designed for solid-state NEMS actuation where manipulation and assembly of nanoscale objects are required. For applications in nanomedecine such as novel drug delivery NEMS capable to perform controlled and targeted drug delivery into cells, performances of nanotube actuators are limited due to the operation of high electrostatic fields in liquid mediums [167], [168]. It is the reason why proteins represent fertile territory for nanoscale mechatronics that produce linear motions in liquid environments. As illustration, substantial progress in DNA actuated nanomechanical devices has been initiated [169] through controlled variations of the physiological medium (temperature, acidic concentration, salt, ionic level). DNA undergoes a substantial mechanical denaturating transition (A$\mathrm{T}$ and G-C base pairs tend to unbind locally) at the origin of DNA actuated nanomechanical [170]. In approaches toward artificial machinery, a variety of molecular and supramolecular systems have been designed in recent years in which changes in shape, switching processes, or movements occur in response to external chemical, electrochemical [171], light-driven [172] or photochemical [173] stimuli. The control of chirality, being one of the intrinsic features of living nature, was the guiding principle in a synthetic endeavor that ultimately culminated in the control of molecular motion, e.g. chiroptical molecular switches and light-driven unidirectional rotary motors [174]. Controllable and reversible actuation of an array of microcantilever beams has been achieved under redox conditions when a monolayer of bistable linear motor molecules were coated on the beams [175]. Bridging the fields of biology and nanotechnology, the authors in [176] propose a novel concept of encapsulated DNA molecule acting as nanoscale actuator inside carbon nanotubes in a water solute environment. While fully servoed linear NEMS remain a challenge, these investigations demonstrate the possibility of fabricating linear servomotors with integrated position sensing for various future NEMS applications, e.g., untethered nanosystems propelled by magnetotactic bacteria [177], atomic force microscope (AFM)based data storage [178] or on-chip temperature sensing and control for cell immobilization [179].

\section{CONCluding Remarks}

This review tries to be complete in its general scope by reviewing most major works in the field of MEMS/NEMS modeling and control. Though it is impossible (due to the size and time constraints) to list every single work in a review of such a varied and dynamic field, the authors believe that this paper provides the reader with the most up-to-date information about the various advances that have taken place over the years in the modeling and control of MEMS/NEMS devices. With the advent of better, faster computing hardware and dedicated software, it will be prudent to say that the field of MEMS/NEMS is bound to see an even greater influx of academic and industrial interest. As the fields of physics, chemistry, biology and mathematics evolve and fuse together, more realistic models that capture the behavior of these microscale systems most accurately should be a key result. This, in turn, will combine with the fast developments occurring in the areas of very high device density chip fabrications and flexible electronics to produce control techniques that will make the desirable performance of a MEMS/NEMS device easily realizable, robust and adaptive.

\section{ACKNOWLEDGMENTS}

The authors would like to thank all the past and present researchers in the field of MEMS/NEMS, control theory and modeling. This work would not be realizable without their efforts in the first place.

\section{REFERENCES}

[1] R. Feynman, "There's plenty of room at the bottom," Lecture at the American Physical Society meeting at Caltech on $29^{\text {th }}$ December, 1959.

[2] N. Taniguchi, "On the basic concept of "nano-technology'," Proceedings of the International Conference of Production Engineering (Japan Society of Precision Engineering and International Institution for Production Engineering Research), Tokyo Part II, 1974.

[3] H. W. Kroto, J. R. Heath, S. C. O'Brien, R. F. Curl, and R. E. Smalley, "C ${ }^{60}$ : Buckminsterfullerene," Nature, vol. 318, pp. 162 - 163, 1985.

[4] G. Binnig and H. Rohrer, "Scanning tunneling microscopy," IBM Journal of Research and Development, vol. 30, no. 4, 1986.

[5] K. E. Drexler, Engines of Creation: The Coming Era of Nanotechnology. Doubleday, 1986.

[6] H. C. Nathanson, W. E. Newell, R. A. Wickstrom, and J. Davis, J. R., "The resonant gate transistor," IEEE Transactions on Electronic Devices, vol. 14, pp. 117 - 133, 1967.

[7] X. Chen, D. F. Cui, C. C. Liua, and H. Lia, "Microfluidic chip for blood cell separation and collection based on crossflow filtration," Sensors and Actuators B: Chemical, vol. 130, pp. 216 - 221, 2008.

[8] M. Despont, J. Brugger, U. Drechsler, U. Drig, W. Hberle, M. Lutwyche, H. Rothuizen, R. Stutz, R. Widmer, G. Binnig, H. Rohrer, and P. Vettiger, "VLSI-NEMS chip for parallel afm data storage," Sensors and Actuators A: Physical, vol. 80 (2), pp. $100-$ 107, 2000.

[9] H. Yamaguchi, S. Miyashita, and Y. Hirayama, "InAs/AlGaSb heterostructure displacement sensors for MEMS/NEMS applications," Proceedings of the International Conference on Molecular Beam Epitaxy, vol. 251, pp. 556 - 559, 2003.

[10] V. Gayathri and R. Geetha, "Carbon nanotube as NEMS sensor effect of chirality and stone-wales defect intend," Journal of Physics: Conference Series, vol. 34, pp. 824 - 828, 2006.

[11] X. Li, J. Han, H. Bao, and Z. Yang, "Integrated spm probes with NEMS technology," Sensors and Actuators A: Physical, vol. 133 (2), pp. 383 $-387,2007$

[12] J.-H. Park, C.-H. Lee, Y.-H. Park, Y.-D. Kim, C.-H. Ji, J. Bu, and H.-J. Nam, "A fully wafer-level packaged RF MEMS switch with low actuation voltage using a piezoelectric actuator," Journal of Micromechanics and Microengineering, vol. 16, pp. 2281 - 2286, 2006.

[13] I. Kanno, S. Tsuda, and H. Kotera, "High-density piezoelectric actuator array for MEMS deformable mirrors composed of PZT thin films," IEEE/LEOS International Conference on Optical MEMs and Nanophotonics, (Freiburg, Germany) 11 - 14 August, pp. 132 - 133, 2008.

[14] P. Srinivasan and S. Spearing, "Optimal materials selection for bimaterial piezoelectric microactuators," IEEE Journal of Microelectromechanical Systems, vol. 17, no. 2, pp. 462 - 472, April 2008. 
[15] S. Heo and Y. Y. Kim, "Optimal design and fabrication of MEMS rotary thermal actuators," Journal of Micromechanics and Microengineering, vol. 17, pp. $2241-2247,2007$.

[16] G. K. Lau, J. F. L. Goosen, F. van Keulen, T. Chu Duc, and P. M. Sarro, "Polymeric thermal microactuator with embedded silicon skeleton: Part idesign and analysis," IEEE Journal of Microelectromechanical Systems, vol. 17, no. 4, pp. 809 - 822, August 2008.

[17] J. D. Grade, H. Jerman, and T. W. Kenny, "Design of large deflection electrostatic actuators," IEEE Journal of Microelectromechanical Systems, vol. 12, pp. $335-343,2003$.

[18] R. Kornbluh, "Dielectric elastomer actuators: muscles that morph," ICASE Lecture Series on Morphing (Hampton, VA: NASA Langley Research Center), 2001.

[19] T. Tanaka, K. Saeki, and K. Matsuki, "Dynamic characteristics of high field electro-active silicone and acrylic elastomer actuator devices," IEEE Conference on Electrical Insulation and Dielectric Phenomena, (Kansas City, Missouri, USA), 15 - 18 October, pp. 202 - 205, 2006.

[20] D. J. Bell, T. J. Lu, N. A. Fleck, and S. M. Spearing, "Mems actuators and sensors: observations on their performance and selection for purpose," Journal of Micromechanics and Microengineering, vol. 15 (2), pp. S152 - S164, 2005.

[21] V. Kolchuzhin, J. Mehner, T. Gessner, and W. Doetzel, "Parametric finite element analysis for reduced order modeling of MEMS," International Conference on Thermal, Mechanical and Multi-Physics Simulation and Experiments in Microelectronics and Micro-Systems, (20-23 April), pp. 1 - 6, 2008.

[22] S. E. Lyshevski, "Modeling and control of MEMS with high speed synchronous micromotors and controllers/drivers-on-VLSI-chip ICs," Energy Conversion and Management, vol. 44, pp. 667 - 679, 2003.

[23] S. De and N. Aluru, "Physical and reduced-order dynamic analysis of MEMS," International Conference on Computer Aided Design, 9-13 Nov. 2003, pp. $270-273,2003$.

[24] B. Zhang and M. T. E. Kahn, "Overview and improving fiber optic gyroscope based on MEMS/NEMS fabrication," Proceedings of the International MEMS Conference, vol. 34, pp. 148 - 154, 2006.

[25] T. Bechtold, E. Rudnyi, and J. Korvink, "Automatic order reduction of thermo-electric models for mems: Arnoldi versus guyan," Fourth International Conference onAdvanced Semiconductor Devices and Microsystems, (14-16 October), vol. 3, pp. 333 - 336, 2002.

[26] J. S. Han, E. B. Rudnyi, and J. G. Korvnik, "Efficient optimization of transient dynamic problems in MEMS devices using model order reduction," Journal of Dynamic Systems, Measurement and Control, vol. 15, pp. $822-832,2005$.

[27] C. Chen and C. Lee, "Design and modeling for comb drive actuator with enlarged static displacement," Sensors and Actuators A, vol. 115 , pp. $530-539,2004$

[28] W. Zhang, G. Meng, and H. Li, "Adaptive vibration control of microcantilever beam with piezoelectric actuator in MEMS," International Journal of Advanced Manufacturing Technology, vol. 28, pp. 321 $327,2006$.

[29] J. Jinghong Chen; Sung-Mo Kang; Jun Zou; Chang Liu; Schutt-Aine, "Reduced-order modeling of weakly nonlinear MEMS devices with taylor-series expansion and arnoldi approach," JMEMS, vol. 13, no. 3, pp. $441-451$, June 2004

[30] X. Lin, Z. Chen, and J. Ying, "Macromodeling of the electrostatically actuated rectangle plate based on modal projection," International Conference on Mechatronics and Automation, (5-8 August), pp. 2741 - 2746, 2007.

[31] G. Fedder, "Issues in MEMS macromodeling," 2003 International Workshop on Behavioral Modeling and Simulation, (7-8 October), pp. $64-69,2003$

[32] J. Mehner, J. Wibbeler, and F. Bennini, "Ansys multiphysics capabilities for mems modeling and simulation - part 3: Exporting macromodels for circuit and system simulation tools." ANSYS Solutions, www.ansys.com, 2008

[33] G. Lorenz, A. Morris, and I. Lakkis, "A top-down design flow for moems," IEEE International Conference on Micro-Electo-Mechanical Systems, Jan. 20- 24, 2002, Las Vegas, NV, USA, pp. $204-209,2002$.

[34] —, "A top-down design flow for MOEMS," SPIE - 4408, Design, Test, Integration, and Packaging of MEMS/MOEMS, (25-27 April) Cannes, France, pp. 126 - 137, 2001

[35] G. K. Fedder and Q. Jing, "A hierarchical circuit-level design methodology for microelectromechanical systems," IEEE Transactions on Circuits and Systems-II, vol. 46, no. 10, pp. 1309 - 1315, September 1999.

[36] W. Xue, J. Wang, and T. Cui, "Modeling and design of polymerbased tunneling accelerometers by ANSYS/MATLAB," IEEE/ASME
Transactions on Mechatronics, vol. 10, no. 2, pp. 468 - 472, April 2005.

[37] N. A. Y. Xu, "Multiscale electrostatic analysis of silicon nems via heterogeneous quantum models," Physical Review B, vol. 77 (7), p. 075313, 2008 .

[38] B. Borovic, C. Hong, X. M. Zhang, A. Q. Liu, and F. L. Lewis, "Open vs. closed-loop control of the MEMS electrostatic comb drive," Proceesings of the $13^{\text {th }}$ Mediterranean Conference on Control and Automation, 2005.

[39] S. M. F. Shi, P. Ramesh, "Dynamic analysis of micro-electromechanical systems," International Journal for Numerical Methods in Engineering, vol. 39, no. 24, pp. 4119 - 4139, December 1998.

[40] J. Xu, W. Yuan, H. Chang, X. Lu, and Y. Yu, "Hybrid macromodels for modeling and simulation of a $\mathrm{z}$-axis micro accelerometer," 3rd IEEE International Conference on Nano/Micro Engineered and Molecular Systems, (6-9 January), pp. $357-361,2008$.

[41] N. M. Ghoniem, E. N. Busso, N. Kioussis, and H. Huang, "Multiscale modelling of nanomechanics and micromechanics: an overview," Philosophical Magazine, vol. 83, pp. 3475 - 3528, 2003.

[42] B. P. H. E. C.H. Ke, N. Pugno, "Experiments and modeling of carbon nanotube based nems device," Journal of the Mechanics and Physics of Solids, vol. 53, pp. 1314 - 1333, 2005.

[43] W. W. Liou, F. Liu, and Y. Fang, "Navier stokes and dsme simulations of forced chaotic microflows," 33rd AIAA Fluid Dynamics Conference and Exhibit, pp. AIAA 2003-3583, 2003.

[44] B.-Y. Cao, J. Sun, M. Chen, and Z.-Y. Guo, "Molecular momentum transport at fluid-solid interfaces in mems/nems: A review," Int. J. Mol. Sci., vol. 10, 2009.

[45] C. G. L. M. P. H.-R. H. E. Pantazi A., Sebastian A., "Control of memsbased scanning probe data-storage devices," IEEE Transactions on Control Systems Technology, vol. 15, no. 5, pp. 824 - 841, September 2007.

[46] Desquenes, S. V. Rotkin, and N. R. Alaru, Nanotechnology, vol. 13 , no. 6, pp. 120 - 901, December 2002.

[47] P. N. Ke C-H, Espinosa H D, "Numerical analysis of nanotube based nems devices. part ii: Role of finite kinematics, stretching and charge concentrations." J. Appl. Mech., vol. 72, pp. 726 - 731, 2005.

[48] J. W. L. Zhou, H.-Y. Chan, T. K. H. To, K. W. C. Lai, and W. J. $\mathrm{Li}$, "Polymer MEMS actuators for underwater micromanipulation," IEEE/ASME Transactions on Mechatronics, vol. 9, no. 2, pp. 334 342, June 2004.

[49] D. P. B. R. N Kacem, S Hentz and V. Nguyen, "Nonlinear dynamics of nanomechanical beam resonators: improving the performance of nemsbased sensors," Nanotechnology, vol. 20, p. 275501, 2009.

[50] E. H. D. Ke C-H, "Numerical analysis of nanotube based nems devices. part i: Electrostatic charge distribution on multiwalled nanotubes," $J$. Appl. Mech., vol. 72, pp. $721-725,2005$.

[51] Z. Tang, Y. Xu, G. Li, and A. N. R., "Physical models for coupled electromechanical analysis of silicon nanoelectromechanical systems," Journal of Applied Physics, vol. 97, no. 11, pp. 114304.1 - 114304.13 , November 2005 .

[52] J. B. Muldavin and G. M. Rebeiz, "Nonlinear electro-mechanical modeling of MEMS switches," IEEE MTT-S International Microwave Symposium Digest, (20-25 May), vol. 3, pp. $2119-2122,2001$

[53] D. P. L. N. A. Lazaro, A.; Girbau, "Non linear actuation model for lateral electrostatically-actuated dc-contact rf MEMS series switches," Spanish Conference on Electron Devices, Jan. 31-Feb. 2, pp. 181 184, 2007.

[54] A. Boni, G. Fontana, and F. Pianegiani, "Time-domain modeling and characterization of capacitive mems switches," IEEE Conference on Instrumentation and Measurement Technology Conference, 16-19 May 2005, vol. 3, pp. $1808-1811,2005$.

[55] Pelesko, "Mathematical modeling of electrostatics mems with tailored dielectric properties," SIAM Journal of Applied Mathematics, vol. 62, no. 3, pp. $888-908$, February 2002.

[56] Q. Qi, "A computationally efficient model for analyzing an electrostatically driven MEMS device embedded in a dielectric fluid," 7th International Conference on Electronic Packaging Technology, vol. 14, no. 5 , pp. $1-9$, October 2006

[57] G. W. G. Schrag, "Physically-based modeling of squeeze film damping by mixed level simulation"," Sensors and Actuators A., pp. $64-69$, 2001.

[58] E. S. Hung and S. D. Senturia, "Dynamical models for microelectromechanical systems from a few finite-element simulation runs," IEEE/ASME Journal of Microelectromechanical Systems, vol. 8, no. 2, pp. 280 - 289, September 1999 
[59] H. Reid and J. White, "Boundary-element modeling of nanoscale device electrostatics," In Sensors, Proceedings of the IEEE, vol. 3, pp. $1403-1406,2009$.

[60] V. Kolchuzhin, W. Doetzel, and J. Mehner, "A derivatives-based method for parameterization of MEMS reduced order models," International Conference on Thermal, Mechanical and Multi-Physics Simulation and Experiments in Microelectronics and Micro-Systems, 20-23 April 2008, pp. $1-5,2005$.

[61] M. I. Younis, E. M. Abdel-Rahman, and A. Nayfeh, "A reducedorder model for electrically actuated microbeam-based MEMS," IEEE Journal of Microelectromechanical Systems, vol. 12, no. 5, pp. $672-$ 680, October 2003.

[62] P. E. S. and B. K. S., "Numerical modeling of micromechanical devices using the direct simulation monte carlo method," Journal of fluids engineering, vol. 118, pp. $464-469,1996$.

[63] J. Xu, W. Yuan, H. Chang, X. Lu, and Y. Yu, "Octree-search kinetic monte carlo algorithm for the simulation of complex $3 \mathrm{~d}$ mems structures," Micro Electro Mechanical Systems, 2008. MEMS 2008. IEEE 21st International Conference on, pp. 323 - 326, 2008.

[64] H. Somada, K. Hirahara, S. Akita, and Y. Nakayama, "A molecular linear motor consisting of carbon nanotubes," Nano Letters, vol. 9 , no. 1 , pp. $62-65,2009$.

[65] M. H. L. Z. X. Z.-A. F. B. J. N. L. Dong, X. Tao, "Nanotube boiler: Attogram copper evaporator driven by electric current, joule heating, charge, and ionization," IEEE Transactions on Nanotechnology, vol. 8, pp. $565-568,2009$

[66] S. P. et al., "Molecular dynamic study on-size dependent elastic properties of the silicon nanocantilevers," Thin Solid Films, vol. 492, pp. $285-289,2005$

[67] S. Zhang, W. Kim, and R. S. Ruoff, "Atomistic simulations of doublewalled carbon nanotubes as rotational bearings," Nano Letters, vol. 4 , pp. 293 - 297, 2004.

[68] R. E. Rudd, "Coarse-grained molecular dynamics and multiscale modeling of NEMS resonators," Technical Proceedings of the International Conference on Computational Nanoscience and Nanotechnology, 2002.

[69] K. Esfarjani and G. A. Mansoori, "Statistical mechanical modeling and its application to nanosystems," Handbook of Theoretical and Computational Nanotechnology, vol. 1, pp. 1 - 45, 2005.

[70] S. J. Tans, M. H. Devoret, H. Dal, A. Thess, R. Smalley, L. Geerligs, and C. Dekker, "Single-wall carbon nanotube as quantum wires," Nature, vol. 386, pp. 474 - 477, 1997.

[71] D. Maithripala, B. Kawade, I. Wickramasinghe, J. Berg, and W. Dayawansa, "A passivity-based controller for an electrostatic MEMS model in the presence of parasitics," International Conference on Industrial and Information Systems, (9-11 August), pp. 267 - 272, 2007.

[72] S. Mariani, A. Ghisi, C. A., and Z. S., "Modeling impact-induced failure of polysilicon nems: A multi-scale approach," Sensors, vol. 9, pp. $556-567 ;, 2009$.

[73] A. N., "Hierarchical physical models for analysis of electrostatic nanoelectromechanical systems (nems)," Automatica, vol. http://nanohub.org/resources/850, 2006.

[74] M. Bernashi, S. Melchionna, S. Succi, M. Fyta, and E. Kaxiras, "Quantized current blockade and hydrodynamic correlations in biopolymer translocation through nanopores: Evidence from multiscale simulations," vol. 8, no. 4, pp. 1115 - 1119, 2008.

[75] M. Hamdi and A. Ferreira, "Dna nanorobotics," Microelectronics Journal, vol. 39, pp. 1051 - 1059, 2008.

[76] _ - "Computational design and multiscale modeling of a nanoactuator using dna actuation," Nanotechnology, vol. 20, p. 485501, 2009.

[77] T. Karakasidis and C. Charitidis, "Multiscale modeling in nanomaterials science," Materials Science and Engineering C, vol. 27, pp. 1082 $-1089,2007$.

[78] A. C. T. et al., "Materials integrity in microsystems: a framework for a petascale predictive-science-based multiscale modeling and simulation system," Comput. Mechanics, vol. 42, pp. 485 - 510, 2008.

[79] K. E. W. C. P.-E. J. S. M. Odegard, T. S. Gates, "Effect of nanotube functionalisation on the elastic properties of polyethylene nanotube composites," AIAA Journal, vol. 43, no. 8, pp. 1828 - 1835, August 2005 .

[80] T. M. W. F. H. Kubo, M. Ciappa, "Multiscale simulation of aluminium thin films for the design of hihly-reliable mems devices," Microelectronics Reliability, vol. 49, pp. 1278 - 1282, 2009.

[81] H. Adalsteinsson, B. J. Debusschere, K. R. Long, and H. N. Najm, "Components for atomistic-to-continuum multiscale modeling of flow in micro- and nanofluidic systems," Sci. Program., vol. 16, no. 4, pp. $297-313,2008$.
[82] G. Lu and E. Kaxiras, "Overview of multiscale simulations of materials," Handbook of Theoretical and Computational Nanotechnology, vol. 1 , pp. $1-33,2005$.

[83] G. Li and N. R. Aluru, "Hybrid techniques for electrostatic analysis of nanoelectromechanical systems," Journal of Applied Physics, vol. 96 , pp. $2221-2231,2004$.

[84] A. Lombo-Carrasquilla and G. Becerra-Forigua, "Integrated modeling methodology for nanoscale electronic devices," 3rd IEEE International Conference on Nano/Micro Engineered and Molecular Systems, 6-9 Jan. 2008, pp. $357-361,2008$.

[85] D. W. Wood and L. Bijnens, "Multiphysics modeling of axispherical MEMS," 7th AFRICON Conference in Africa, vol. 2, pp. 1017 - 1022 , 2004.

[86] A. Ferreira, J. Agnus, N. Chaillet, and J.-M. Breguet, "A smart microrobot on chip: Design, identification and control," IEEE/ASME Transactions on Mechatronics, vol. 9, no. 3, pp. 508 - 519, September 2004.

[87] R. Oboe, R. Antonello, E. Lasalandra, G. Durante, and L. Prandi, "Control of a z-axis MEMS vibrational gyroscope," IEEE/ASME Transactions on Mechatronics, vol. 10, no. 4, pp. 364 - 370, August 2005

[88] B. Borovic, F. Lewis, D. Agonafer, E. Kolesar, M. Hossain, and D. Popa, "Method for determining a dynamical state-space model for control of thermal MEMS devices," IEEE Journal of Microelectromechanical Systems, vol. 14, no. 5, pp. 961 - 970, October 2005.

[89] B. C. J. S. C. Lee, Y.C. Amir Parviz, "Packaging for microelectromechanical and nanoelectromechanical systems," IEEE Transactions on Advanced Packaging, vol. 26, no. 3, pp. 217 - 226, August 2002.

[90] N. S. O. Lishchynska, M.; Cordero, "State of the art in prediction of mechanical behaviour of microsystems [mems]," 5th International Conference on Thermal and Mechanical Simulation and Experiments in Microelectronics and Microsystems, pp. 287 - 294, 2004.

[91] M. d. B. M. K. J. E. P. E. W. C. H. L. Redmond, J.; Reedy D.; Heinstein, "Microscale modeling and simulation," SANDIA Report, SAND20013675, December 2001, pp. 287 - 294, December 2001.

[92] P. D. S. T. H. S. W. D. M. H. Innocent, M.; Wambacq, "An analytic volterra-series-based model for a MEMS variable capacitor," IEEE Transactions on Computer-Aided Design of Integrated Circuits and Systems, vol. 22, no. 2, pp. 124 - 131, February 2003.

[93] M. Z. M. Litovski, V.; Andrejevic, "Ann based modeling, testing and diagnosis of MEMS: Capacitive pressure transducer example," 7th Seminar on Neural Network Applications in Electrical Engineering, 23-25 Sept. 2004, pp. 183 - 188, 2004.

[94] L. Bleris and M. Kothare, "Real-time implementation of model predictive control," American Control Conference, 8-10 June 2005, vol. 6 , pp. 4166 - 4171, 2005.

[95] M. Bazu, C. Tibeica, L. Galateanu, and V. E. Ilian, "Fuzzy-logic reliability predictions in microtechnologies," International Conference on Computational Intelligence for Modelling, Control and Automation and International Conference on Intelligent Agents, Web Technologies and Internet Commerce, vol. 1, pp. 89 - 93, 2005.

[96] J. L. R. F. C. J. R. D. Singh, P.; Rajagopalan, "Fuzzy logic-based microbattery controller for mems applications," 35th Intersociety Energy Conversion Engineering Conference and Exhibit, vol. 2, pp. 747 - 751 , 2000.

[97] B. Borovic, A. Q. Liu, D. Popa, H. Cai, and F. L. Lewis, "Openloop versus closed-loop control of MEMS devices: choices and issues,' IEEE Journal of Microelectromechanical Systems, vol. 15, pp. 1917 1924, 2005.

[98] W. Tang, T. Nguyen, and R. Howe, "Laterally driven polysilicon resonant microstructures," Sensors and Actuators A, vol. 20, pp. 25 $-32,1989$.

[99] W. Hofman, C. Lee, and N. MacDonald, "Monolithic three-dimensional single-crystal silicon microelectromechanical systems," Sensors and Materials, vol. 10, pp. 337 - 350, 1998.

[100] K. M. Morzinski, K. B. W. Harpsie, D. T. Gavel, and S. M. Ammons, "The open-loop control of MEMS : Modeling and experimental results," Proceedings of SPIE, vol. 6467, pp. 64 670G.1 - 64 670G.10, 2007.

[101] S. Huang, J. Tsai, D. Hah, H. Toshiyoshi, and M. C. Wu, "Open-loop operation of MEMS WDM routers with analog micromirror array," Proceedings of the IEEE/LEOS International Conference on Optical MEMs, pp. 179 - 180, 2002.

[102] J. Tsai, S. Huang, D. Hah, H. Toshiyoshi, and M. Wu, "Open-loop operation of MEMS-based $1 \mathrm{~N}$ wavelength-selective switch with longterm stability and repeatability," IEEE Photonics Technology Letters, vol. 16 (4), pp. 1041 - 1043, 2004. 
[103] B.-W. Yoo, J.-H. Park, Y.-H. Jang, and Y.-K. Kim, "A low-drift, openloop controlled, single crystalline silicon micromirror with floating field-limiting shields," Journal of Micromechanics and Microengineering, vol. 18, p. 035031(8pp), 2008.

[104] C. R. Vogel and Q. Yang, "Modeling, simulation, and open-loop control of a continuous facesheet mems deformable mirror." Journal of the Optical Society of America A: Optics, Image Science and Vision, vol. 23 (5), pp. 1074 - 1081, 2006.

[105] B. D. Jensen, S. Mutlu, S. Miller, K. Kurabayashi, and J. J. Allen, "Shaped comb fingers for tailored electromechanical restoring force," IEEE Journal of Microelectromechanical Systems, vol. 12, pp. 373 383,2003

[106] H. J. Kordlar and G. Rezazadeh, "Modeling open-loop MEMS tunneling accelerometer based on circular plate," Sensors \& Transducers Journal, vol. 78(4), pp. 1083 - 1092, 2007.

[107] D. Keymeulen, M. I. Ferguson, B. Oks, C. Peay, R. Terrile, Y. Cheng, D. Kim, E. MacDonald, and D. Foor, "Hardware platforms for MEMS gyroscope tuning based on evolutionary computation using open-loop and closed -loop frequency response." Proceedings of the International Conference on Evolvable Systems, Barcelona, Spain (September 1214), 2005.

[108] M. F. Daqaq, C. K. Reddy, and A. H. Nayfeh, "Input-shaping control of nonlinear MEMS," Nonlinear Dynamics, vol. 54 (1-2), pp. 167 179, 2008.

[109] D. O. Popa, B. H. Kang, J. T. Wen, H. E. Stephanou, G. Skidmore, and A. Geisberger, "Dynamic modeling and input shaping of thermal bimorph actuators," IEEE International Conference on Robotics Automation (Taipei, Taiwan, 1419 Sept.), 2003.

[110] J. B. Stewart, A. Diouf, Y. Zhou, and T. G. Bifano, "Open-loop control of a MEMS deformable mirror for large-amplitude wavefront control." Journal of the Optical Society of America A: Optics, Image Science and Vision, vol. 24 (12), pp. 3827 - 3833, 2007.

[111] C. Acar, S. Eler, and A. M. Shkel, "Concept, implementation, and control of wide bandwidth MEMS gyroscopes," Proceedings of the American Control Conference (June 25 - 27), pp. 1229 - 1234, 2001.

[112] "System and method for canceling disturbance mems devices," United States Patent 6909819, June 21, 2005.

[113] B. Borovic, C. Hong, A. Q. Liu, L. Xie, and F. L. Lewis, "Control of a MEMS optical switch," Proceedings of the 43rd IEEE Conference on Decision and Control (December 14 -17), vol. 5, pp. 3039 - 3044 2004.

[114] "MEMS device control with filtered voltage signal shaping," United States Patent 7428353, September 23, 2008.

[115] V. Milanovic and K. Castelino, "Sub -100 $\mu$ s settling time and low voltage operation for gimbal - less two - axis scanners," Proceedings of the IEEE/LEOS International Conference on Optical MEMS, 2004

[116] T. Fukushige, S. Hata, and A. Shimokhobe, "A new driving method for electrostatic MEMS actuators to prevent sticking," Proceedings of the 4th euspen International Conference ( Glasgow, Scotland, UK, May June), pp. 1 - 2, 2004.

[117] S. Jordan and E. Lawrence, "Vibration nullification of MEMS devices using input shaping," Proceedings of the SPIE Conference on Damping and Isolation (March 3 - 5), vol. 5052, pp. 326 - 334, 2003.

[118] S. E. Lyshevski, MEMS and NEMS: structures, devices, and systems. CRC Press, Boca Raton, FL, 2002.

[119] W.-T. Sung, S. Sung, J.-Y. Lee, T. Kang, Y. J. Lee, and J. G. Lee, "Development of a lateral velocity-controlled MEMS vibratory gyroscope and its performance test," IEEE Journal of Microelectromechanical Systems, vol. 18, p. 055028(13pp), 2008.

[120] H. Cai, J. Wu, L. Z. J, X. M. Wang, Y. X. Lu, and C. Liu, "Optical MEMS switch control and packaging," Proceedings of the 5 TH Conference on Electronics Packaging Technology (December 10 -12), pp. $291-293,2003$.

[121] M. Vagiaa, G. Nikolakopoulos, and A. Tzesa, "Design of a robust PIDcontrol switching scheme for an electrostatic micro-actuator," Control Engineering Practice, vol. 16 (11), pp. 1321 - 1328, 2008.

[122] A. Koide, K. Sato, S. Suzuki, and M. Miki, "A multistep anisotropic etching process for producing 3-d accelerometers," In Technical Digest of the $11^{\text {th }}$ Sensor Symposium, 1992

[123] K. Ikeda, H. Kuwayama, T. Kobayashi, T. Watanabe, T. Nishikawa, T. Yoshida, and K. Harada, "Three-dimensional micromachining of silicon pressure sensor integrating resonant strain gauge on diaphragm," Sensors and Actuators A, pp. A21 - A23: 1007 - 1009, 1990

[124] — "Silicon pressure sensor integrates resonant strain gauge on diaphragm," Sensors and Actuators A, pp. A21 - A23: 146 - 150, 1990 .
[125] J. Bryzek, E. Abbott, A. Flannery, D. Cagle, and J.Maitan, "Contro issues for MEMS," Proceedings of the $42^{\text {nd }}$ International Conference Decision and Control, pp. 3039 - 3047, 2003.

[126] "MEMS device with feedback control," United States Patent 7061660, June 13, 2006

[127] A. Shkel, R. Horowitz, A. Seshia, S. Park, and R. Howe, "Dynamics and control of micromachined gyroscopes," Proceedings of the American Control Conference (June 2 - 4), vol. 3, pp. 2119 - 2124, 1999.

[128] Y. Chen, R. M'Closkey, T. Tran, and B. Blaes, "A control and signal processing integrated circuit for the jpl-boeing micromachined gyroscopes," IEEE Trans. Control Systems Technology, vol. 13 (2), pp. $286-300,2005$.

[129] "Integrated low power digital gyro control electronics," United States Patent 6915215, July 5, 2005.

[130] C. C. Painter and A. M. Shkel, "Active structural error suppression in MEMS vibratory rate integrating gyroscopes," IEEE Sensors Journal, vol. 3 (5), pp. 595 - 606, 2003.

[131] H. Rodjegard, D. Sandstrom, P. Pelin, M. Carlsson, M. Bohman, N. Hedenstierna, G. Andersson, and I. AB, "A novel architecture for digital control of MEMS gyros," In Sensors, Proceedings of the IEEE, vol. 3, pp. 1403 - 1406, 2004.

[132] M. Looney, "Optimizing MEMS gyroscope performance with digital control," Analog Devices Application Note (AN-942).

[133] S. Park, R. Horowitz, and C. woo Tan, "Adaptive control for MEMS gyroscopes," California PATH Research Report, vol. UCB-ITS-PRR 2002-11, 2002

[134] S. Park and R. R. Horowitz, "Adaptive control for the conventional mode of operation of MEMS gyroscopes," IEEE Journal of Microelectromechanical Systems, vol. 12 (1), pp. 101 - 108, 2003.

[135] C. Batur, T. Sreeramreddy, and Q. Khasawneh, "Sliding mode control of a simulated MEMS gyroscope," Proceedings of the American Control Conference (8 - 10 June), vol. 6, pp. 4160 - 4165, 2005.

[136] J. Fei and C. Batur, "Robust adaptive control for a MEMS vibratory gyroscope," International Journal of Advanced Manufacturing Technology (July 4), vol. 1433-3015 (online), 2008.

[137] Q. Zheng, L. Dong, and Z. Gao, "A novel control system design for vibrational MEMS gyroscopes," Sensors and Actuators A, vol. 78, pp. 1073 - 1082, 2007.

[138] R. P. Leland, "Adaptive control of a MEMS gyroscope using lyapunov methods," IEEE Trans. of Control Systems Technology, vol. 14 (2), pp. $278-283,2006$.

[139] S. Park and R. Horowitz, "Discrete time adaptive control for a MEMS gyroscope," International Journal of Adaptive Control and Signal Processing, vol. 19 (6), pp. 485 - 503, 2005.

[140] M. S. C. Lu and G. K. Fedder, "Position control of parallel-plate microactuators for probe-based data storage," IEEE Journal of Microelectromechanical Systems, vol. 13(5), pp. 759 - 769, 2004.

[141] X. Wu, T. Ren, and L. Liu, "Active damping of a piezoelectric MEMS acoustic sensor," Integrated Ferroelectrics, vol. 80, pp. 317 - 329, 2006

[142] A. Izadian, L. Hornak, and P. Famouri, "Adaptive control of MEMS devices," Proceedings of the Conference for Intelligent Systems and Control (August 14 - 16), 2006.

[143] P. Chu, I. Brener, P. Chuan, L. Shi-Sheng, J. I. Dadap, P. Sangtae, K. Bergman, N. H. Bonadeo, T. Chau, C. Ming, R. Doran, R. Gibson, R. Harel, J. J. Johnson, C. D. Lee, D. R. Peale, T. Bo, D. T. K. Tong, T. Ming-Ju, W. Qi, W. Zhong, E. L. Goldstein, L. Y. Lin, and J. A. Walker., "Design and nonlinear servo control of MEMS mirrors and their performance in a large port-count optical switch," IEEE Journal of Microelectromechanical Systems, vol. 14 (2), pp. 261 - 273, 2005.

[144] J. M. Dawson, J. Chen, K. S. Brown, P. Famouri, and L. A. Hornak, "Through-wafer interrogation of microstructure motion for MEMS feedback control," SPIE Proceedings for the Conference on Miniaturized systems with micro-optics and MEMS : ( Santa Clara CA, 20-22 September), vol. 3878, pp. 281 - 292, 1999.

[145] T. Seki, M. Murakami, J. Yamaguchi, and K. Oda, "High speed mirror control technique for 3D-MEMS optical switch," IEICE Transactions on Communications (Japanese Edition), vol. 189-B, pp. 1315 - 1317 , 2006

[146] P. Song-Hee, A. Aina, T. Denison, and K. Lundberg, "Feedback control for a MEMS-based high-performance operational amplifier," Proceedings of the American Control Conference (30 June - 2 July), vol. 1 (30), pp. 380 - 385, 2004.

[147] M. Afridi, A. Hefner, D. Berning, C. Ellenwood, A. Varma, B. Jacob, and S. Semancik, "MEMS-based embedded sensor virtual components for system-on-a-chip," Solid-State Electronics, vol. 48, pp. 1777 1781, 2004. 
[148] M. Behnam, G. V. Kaigala, M. Khorasani, P. Marshall, C. J. Backhouse, and D. G. Elliott, "An integrated CMOS high voltage supply for labon-a-chip systems," Lab On A Chip, vol. 8, pp. 1524 - 1529, 2008.

[149] C. D. Garca, Y. Liu, P. Anderson, and C. S. Henry, "Versatile 3-channel high-voltage power supply for microchip capillary electrophoresis," Lab On A Chip, vol. 3, pp. 324 - 328, 2003.

[150] T. Fujimori, Y. Hanaoka, K. Fujisaki, N. Yokoyama, and H. Fukuda, "On-chip MEMS capacitive pressure sensor fabricated using standard CMOS back-end-of-line processes," Technical Digest: Sensors Symposium, vol. 22, pp. $224-227,2005$.

[151] O. Brand and H. Baltes, "Microsensor packaging," Microsystems technology, vol. 7, pp. $205-208,2000$.

[152] C. Hagleitner, A. Hierlemann, D. Lange, A. Kummer, N. Kerness, O. Brand, and H. Baltes, "Smart single-chip gas sensor microsystem," Nature, vol. 414, pp. 293 - 296, 2001.

[153] Y. Xu, C.-W. Chiu, F. Jiang, Q. Lin, and Y.-C. Tai, "A MEMS multisensor chip for gas flow sensing," Sensors and Actuators A: Physical, vol. 121 (1), pp. 253 - 261, 2005.

[154] M. S.-C. Lu, Z.-H. Wu, C.-E. Huang, S.-J. Hung, M.-H. Chen, and Y.-C. King, "CMOS micromachined grippers with on-chip optical detection," IEEE Journal of Microelectromechanical Systems, vol. 17, pp. $482-488,2007$.

[155] T. Vestad, D. W. M. Marr, and J. Oakey, "Flow control for capillarypumped microfluidic systems," Journal of Micromechanics and Microengineering, vol. 14, pp. 1503 - 1506, 2004.

[156] C. J. Easley, J. M. Karlinsey, J. M. Bienvenue, L. A. Legendre, M. G. Roper, S. Feldman, M. A. Hughes, E. L. Hewlett, T. J. Merkel, J. P. Ferrance, and J. P. Landers, "A fully integrated microfluidic genetic analysis system with sample-inanswer-out capability," Proceedings of the National Academy of Sciences, U.S.A, vol. 103, pp. 19272 - 19277, 2006.

[157] M. G. Pollack, R. B. Fair, and A. D. Shenderov, "Electrowettingbased actuation of liquid droplet for microfluidic applications," Applied Physics Letters, vol. 77, pp. 1725 - 1726, 2000.

[158] H. Ren, R. B. Fair, and M. G. Pollack, "Automated on-chip droplet dispensing with volume control by electro-wetting actuation and capacitance metering," Sensors and Actuators, B, vol. 98, pp. 319 - 327, 2004.

[159] J. Gong and C. J. Kim, "All-electronic droplet generation on-chip with real-time feedback control for EWOD digital microfluidics," Lab On A Chip, vol. 8, pp. 898 - 906, 2008.

[160] R. Anderson, B. Kawade, K. Ragulan, D. H. S. Maithripala, J. M. Berg, R. O. Gale, and W. P. Dayawansa, "Integrated charge and position sensing for feedback control of electrostatic MEMS," Proceedings of the Conference on Sensors and Smart Structures Technologies for Civil, Mechanical, and Aerospace Systems (March 7 - 10), vol. 5765, 2005.

[161] S. B. Prakash, P. Abshire, M. Urdaneta, M. Christophersen, and E. Smela, "A CMOS potentiostat for control of integrated MEMS actuators," Proceedings of the IEEE International Symposium on Circuits and Systems (May 21 - 24), pp. 5555 - 5558, 2006.

[162] K. Jensen, K. Kim, and A. Zettl, "An atomic-resolution nanomechanical mass sensor." Nature Nanotechnology, vol. 3 (9), pp. 533 - 537, 2008

[163] F. Arai, P. Liu, L. X. Dong, and T. Fukuda, "Field emission property of individual carbon nanotubes and its application," IEEE International Conference on Robotics and Automation, New Orleans, LA, Apr.26May 1, vol. 386, pp. 440 - 445, 2004.

[164] J. Cumings and A. Zettl, "Using dna to construct and power a nanoactuator," Science, vol. 289, p. 602, 2000.

[165] A. M. Fennimore, T. D. Yuzvinsky, W.-Q. Han, M. S. Fuhrer, J. Cumings, and A. Zettl, "Rotational actuators based on carbon nanotubes," Nature, vol. 424, pp. 408 - 410, 2003.

[166] L. Dong, B. Nelson, and F. A. T. Fukuda, "Towards nanotube linear servomotors," IEEE Transactions on Automation Science and Engineering, vol. 3, pp. $228-234,2006$.

[167] N. Sinja and J. T.-W. Yeow, "Carbon nanotubes for biomedical applications," IEEE Transactions On NanoBioscience, vol. 4, pp. 45 - 59, 2005.

[168] R. A. Freitas, "The future of nanofabrication and molecular scale devices in nanomedecine," Study Health Technology Inf., vol. 80, pp. $45-59,2002$.

[169] F. C. Simmel and B. Yurke, "Using dna to construct and power a nanoactuator," Physical Review E, vol. 63, pp. 127 - 132, 2001.

[170] W. B. Sherman and N. C. Seeman, "A precisely controlled dna biped walking device," Nano Letters, vol. 4, pp. 1203 -1207, 2004.

[171] B. L. Feringa, W. F. Jager, and B. de Lange, "Organic materials for reversible optical data storage," Tetrahedron, vol. 49, pp. 8267 - 8310, 1993.
[172] N. Koumura, E. M. Geertsema, A. Meetsma, and B. L. Feringa, "Lightdriven molecular rotor: Unidirectional rotation controlled by a single stereogenic center," Journal of the American Chemical Society, vol. 122(48), pp. 12005 - 12006, 2000.

[173] K. Mislow, "Molecular machinery in organic chemistry," ChemtractsOrganic Chemistry, vol. 2, p. 151, 1989.

[174] R. A. vanDelden and B. L. Feringa, "Light-driven molecular motors," Electronic Properties of Synthetic Nanostructures (edited by H. Kuzmany et al), vol. CP723, pp. 498 - 502, 2004.

[175] X. Huang, R. Horowitz, and Y. Li, "A comparative study of MEMS microactuators for use in a dual-stage servo with an instrumented suspension," IEEE/ASME Transactions on Mechatronics, vol. 11, no. 5, pp. $524-532$, October 2006

[176] M. Hamdi and A. Ferreira, "Multiscale design and modeling of proteinbased nanomechanisms for nanorobotics," International Journal of Robotics Research, vol. 28, pp. 436 - 449, 2009.

[177] S. Andr W.and Martel, "Micro-photovoltaic cells designed for magnetotaxis-based controlled bacterial microrobots," IEICE Electronics Express, vol. 5, no. 3, pp. 101 - 106, 2008.

[178] M. Despont, U. Drechsler, R. Yu, H. Pogge, and P. Vettiger, "Waferscale microdevice transfer/interconnect: its application in an afmbased data-storage system," IEEE Journal of Microelectromechanical Systems, vol. 13, no. 6, pp. 895 - 901, December 2004.

[179] F. Yu-Ching Lin Yamanishi, Y. Arai, "On-chip temperature sensing and control for cell immobilization," 2nd IEEE International Conference on Nano/Micro Engineered and Molecular Systems, Bangkok, China., pp. 659 - 663, June 2007 